\title{
Beyond Alzheimer's Disease: Bilingualism and Other Types of Neurodegeneration
}

Toms Voits (ORCID: 0000-0001-7223-8446) a $^{\mathrm{a}^{*}}$, Christos Pliatsikas (ORCID:

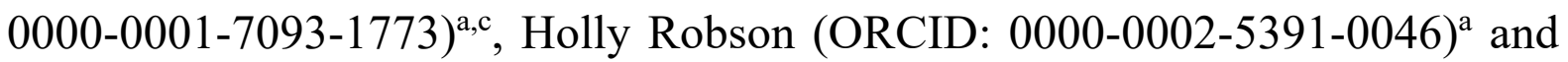
Jason Rothman ${ }^{\mathrm{b}, \mathrm{c}}$

a School of Psychology and Clinical Language Sciences, University of Reading, Harry Pitt Building, Earley Gate, Whiteknights Road, Reading, RG6 6AL, UK.

${ }^{b}$ Department of Language and Culture, The University of Tromsø, Hansine Hansens veg 18, 9019, Tromsø, Norway

'Facultad de Lenguas y Educación, Universidad Nebrija, Calle de Sta. Cruz de Marcenado, 27, 28015, Madrid, Spain

\footnotetext{
" Corresponding author at: School of Psychology and Clinical Language Sciences, University of Reading, Harry Pitt Building, Earley Gate, Whiteknights Road, Reading, RG6 6AL, UK.

Email address: toms.voits@pgr.reading.ac.uk

Fax: +44 (0) 1189753365
} 


\begin{abstract}
Bilingualism has been argued to have an impact on cognition and brain structure. Such effects have been reported in healthy children and young adults, but also in ageing adults, including clinical ageing populations. For example, bilingualism may significantly contribute to the delaying of the expression of Alzheimer's dementia symptoms. If bilingualism plays an ameliorative role against neurodegeneration, it is possible that it would have similar effects for other neurodegenerative disorders, including Multiple Sclerosis, Parkinson's and Huntington's Diseases; however, relevant evidence remains limited. Herein, we provide a focused literature review on the effects of these progressive neurological disorders on cognition and brain structure, examine how the affected functions and brain regions map to those suggested to be impacted by bilingualism, and report the limited evidence of the impact of bilingualism on these conditions. We then examine the value of making links across neurodegenerative disorders and bilingualism, proposing that available evidence warrants claims for bilingualismrelated effects more generally, with an eye at future research to fill in gaps in our understanding.
\end{abstract}

\title{
Keywords
}

Bilingualism; neurodegeneration; cognitive reserve; neural reserve; Huntington's Disease; Parkinson's Disease; Multiple Sclerosis; Alzheimer's Disease; Mild Cognitive Impairment 


\section{Introduction}

The brain adapts, structurally and functionally, in response to new experiences and acquired skills, such as learning a musical instrument or participating in sports (see Chang, 2014, for a review). Such findings have led researchers to investigate whether the acquisition/learning and/or management of more than one language would also affect the structure and function of the bilingual brain (e.g., Bialystok et al., 2004, 2012; Gold et al., 2013; Luk and Pliatsikas, 2016). Active bilingualism stands out as a good candidate due to its ubiquity in daily life coupled with the fact that both languages are always simultaneously active in the bilingual brain which constitutes a sustained, highly engaging mental exercise (e.g., Green, 1998; Kroll and Stewart, 1994; Spivey and Marian, 1999). That is, the constant requirement for continuous suppression/inhibition might, in turn, anatomically and functionally affect the underlying neural substrate supporting this operation.

Controlling two or more languages, keeping them separated, and selecting the appropriate one for use in a given context is termed 'bilingual language control' (Abutalebi and Green, 2007). While the precise mechanisms are yet to be established, the general idea is that language control in bilingualism has knock-on effects to domain-general cognition, specifically to executive functions (as defined by Miyake et al., 2000). Irrespective of how they are acquired (i.e. simultaneously or via sequential language acquisition), the presence of more than one language creates mental competition. This is so because all languages are continually active in the brain, irrespective of need or intention. For successful communication to take place, the language(s) not needed/used at any given time must be suppressed/inhibited while the language in active use has to be monitored for any incursions of the other language(s) (e.g., Abutalebi and Green, 2007). Yet the inhibited language must remain idle in the background, since the need to switch language at a second's proverbial notice is something often needed, yet unreliably predictable. Given the task at hand, the executive functions of conflict 
monitoring, updating, interference suppression and working memory are all straightforwardly implicated in the successful juggling of more than one language.

Executive control is the regulation of the set of cognitive processes related to individual executive functions. Constant involvement of the abovementioned executive functions in the mental exercise of bilingual language control, similar to other activities of high engagement (Maguire et al. 2000), is argued to fine-tune executive functioning more globally. This should relate to increased executive control and improved efficiency in cognitive processing (see Grundy et al., 2017, for review). While subject to ongoing research, there is evidence suggesting at least a partial overlap in the brain areas and neural networks serving bilingual language control and executive functions. This is evidenced by recruitment of these same networks for linguistic and non-linguistic tasks (see Calabria et al., 2018, for review), suggesting that bilingual language control and executive control are not only linked by means of behaviour but also by aspects of supporting neural substrates.

The constructs of cognitive reserve and neural reserve are crucial to the discussion herein. In brief, cognitive reserve is the building up of compensatory cognitive ability, most notable in the presence of neural degeneration. For example, it can be seen when clinical expression of disease symptoms is masked and offset in the presence of brain pathology (Stern, 2002). Neural reserve, however, is progressive "reinforcement" of the brain (increasing grey matter (GM) volume, white matter (WM) integrity, structural and functional connectivity) that makes it more adaptable when facing ageing- or disease-related synaptic or tissue loss (Perani and Abutalebi, 2015). Differently from cognitive reserve, which is seen as an expression of behaviour, neural reserve can be measured directly via neuroimaging. The mechanisms underlying cognitive and/or neural reserve are unclear. One hypothesis is that increased activity in relevant brain areas introduces a greater extent of oxygenation and glucose delivery with cascading beneficial effects, such as increased myelination and potential angiogenesis (Gold, 
2015). While there are many predictors of increased cognitive reserve, such as education and occupational attainment, (active) bilingualism is yet another potential contributor to this mechanism (e.g., Craik et al., 2010). In fact, the accruing effects of bilingualism are potentially more pronounced in lower education, or even illiterate, populations (Alladi et al., 2013; Gollan et al., 2011). This suggests a compounding and overlapping nature of factors contributing to increased cognitive reserve, where presence of one factor, such as higher education, could potentially mask the contribution of other factors, such as bilingualism.

Indeed, examining mind/brain consequences induced by relevant experience with bilingualism has not only been increasingly studied in recent years, but has also met with some debate (see e.g. Antoniou, 2019; Bialystok, 2017; Paap et al., 2015; Valian, 2015, for reviews). To date, the majority of the bilingual cognition literature has examined healthy adult populations, producing mixed results (see Lehtonen et al., 2018, for a recent systematic review). Failure to replicate the same cognitive effects across populations tested under distinct conditions of bilingualism are not, nor should be, surprising per se (see Bak and Robertson, 2017; Bialystok, 2017; Valian, 2015). It does, however, underscore the importance of investigating potential bilingual effects in a more nuanced way to understand what the conditions are, if any, under which bilingualism results in neurocognitive adaptations (Dash et al., 2019; De Cat et al., 2018; DeLuca et al., 2019, 2020; Gullifer and Titone, 2019; Luk and Bialystok, 2013; Sulpizio et al., 2019).

Acknowledging the above epistemological debate is important for any study in this general remit, however, implications of it are of greater or lesser consequence depending on several factors. Since this review concerns the links bilingualism might have with cognitive/neural reserves and thus protective effects to neurodegenerative disorders, we the present debates are of minimal consequence to our goals herein for at least two reasons. Notwithstanding the genuine issues of replication in measuring cognitive functions across all 
bilinguals, one cannot ignore the rather robust body of literature that does show bilingual effects to cognition across the lifespan. While future research must qualify the conditions under which bilingualism impacts domain-general cognition, we are unlikely to be able to confidently exclude any effect at all (but see Paap et al., 2015). Further to the point, while replication is a bona fide issue, it is largely limited to specific measurements on behavioural tasks, for example, with Stroop, Flanker and other similar types of tasks. Given concerns regarding the granularity of such tasks and general replication issues within them regardless of what they are used for (Hedge et al., 2018), it is not clear that replication failures reliably indicate the absence of cognitive adaptations (any more than one could argue these tasks index adaptations if an effect is found). Regardless, the effects of bilingualism on cognition are only part of the story related to potential effects on neurodegeneration anyway. To the extent that bilingualism confers neuroanatomical and functional changes to the brain that can be meaningfully attributed to protection against atypical, pathological decline, conclusions reached in the above debate, independently of the resolution, have limited effects for the present discussion. Therefore, of equal, if not greater, importance is the parallel literature on neuroanatomical changes to the bilingual brain. Bilingual experience changes the physical characteristics of the brain and in areas specifically associated with bilingual language control (see Pliatsikas, 2019, for review). Such changes, for example to GM volume and WM integrity, are of significant relevance to the discussion at hand not the least because neurodegeneration negatively affects them directly (e.g., Auning et al., 2014; Gold et al., 2012; Zarei et al., 2009). Taken together, there is an empirical basis upon which it is reasonable to continue forward with studies examining bilingualism effects on neurodegeneration, regardless of how the debates on cognitive effects turn out. In fact, given that this involves the health sciences in practical terms, there is a moral imperative to do so. 
Indeed, a growing sub-literature on clinical implications of bilingualism for Alzheimer's dementia and Mild Cognitive Impairment (MCI) shows promising results. Our question herein is: How generalizable is this so-called protective factor? Would it extend to neurodegenerative disorders in general, such as Huntington's disease (HD), Parkinson's disease (PD), Multiple Sclerosis (MS) and potentially others? It is reasonable to believe, if on the right track at all, that bilingual experiences should have a similar pattern of delay in the onset of clinical symptoms across neurodegenerative disorders which include executive dysfunction. Herein, we explain: (i) why this should be, (ii) what evidence there currently is to support (or not) this view from neurodegenerative disorders as well as (iii) what directions are recommended to test this hypothesis more directly in the near future.

\section{Motivating the program: Why should this be?}

The first step in contextualizing whether bilingualism provides a protective effect in neurodegeneration disorders in general is to understand what mechanisms might underlie the link between bilingualism and neurocognitive effects, especially regarding what the hypothesized path would be through which bilingualism could have an impact on neurodegenerative diseases. As discussed above, bilingual language control inevitably aligns with domain-general executive control. If some executive functions are more engaged, potentially on a continuum related to bilingual practices such as density of code-switching (Green and Wei, 2016; Hofweber et al., 2016) or patterns of social language use (DeLuca et al., 2020), then this ubiquitous proverbial muscle-flexing over a sustained period of time could lead to the accruing of cognitive reserve and changes to neuroanatomical structure (opportunities for gains in neural reserve) (Pliatsikas et al., 2019). Effects at any point along the life-span continuum, different as their surface manifestations might seem, should, in 
principle, relate back to the same mechanisms and processes as above described. We now turn to what the literatures at various ages indicate.

\subsection{Healthy bilingual brain in young(er) populations}

Studies carried out over the last two decades have shown that (some groups of) bilingual individuals perform better than their monolingual peers in executive control tasks, including working memory tasks (Luo et al., 2013), switching (Calabria et al., 2012), updating (Bialystok et al., 2004), and inhibition (Costa et al., 2008; but see e.g. Valian, 2015, for critical review). Recall from the introduction that monolingual versus bilingual differences are not always attested and, on the back of this, some have questioned the existence of bilingual effects on cognition in general (de Bruin et al., 2015; Lehtonen et al., 2018; Paap et al., 2015; Paap and Greenberg, 2013). As also discussed, even in light of variable data, it is premature to definitively conclude that bilingualism confers no cognitive effects for several reasons, not the least issues of granularity of behavioural measures of executive control. As such, a more reliable outlet to look for traces of potential cognitive and neural reserves is in neuroimaging.

Neuroimaging studies are more consistent in showing changes associated with bilingualism in young(er) populations (from childhood to young adulthood), which include increased cortical and subcortical GM volume, and WM integrity in areas and tracts associated with bilingual language control. Some examples of regions affected include areas related to conflict monitoring and control of language production (anterior cingulate cortex (ACC) and left inferior frontal gyrus (IFG)), areas contributing to switching abilities between languages, (inferior parietal lobule (IPL)), and areas implicated in motor movements and inhibitory control among other roles (basal ganglia) (see Abutalebi, 2008; Abutalebi and Green, 2007). Within the basal ganglia, for example, bilingualism is linked to the increased GM volume in the left caudate nucleus. This structure is implicated in both language control and broader executive 
control (Zou et al., 2012). Even the cerebellum, a structure traditionally associated with the motor system, but also implicated in aspects of executive control (for a review see Bellebaum and Daum, 2007) and language processing, shows increased GM volume in bilinguals (Pliatsikas et al., 2014). WM tracts are also potentially affected by management of two languages. This includes tracts implied in typical language processing, second language acquisition (e.g., inferior fronto-occipital fasciculus (IFOF) bilaterally), and also the strengthening of corpus callosum (CC), implied in domain-general executive control and interhemispheric communication (Hämäläinen et al., 2017; Pliatsikas et al., 2015).

Beyond adaptations to neuroanatomy, recent work provides evidence suggesting adaptations in brain function as well. In other words, bilingualism has an effect not only on the structure of the brain, but also on its functional organisation (e.g. Anderson et al., 2018; DeLuca at el., 2019, 2020). For example, Anderson and colleagues (2018) found that monolingual and bilingual individuals differ in cognitive network recruitment for the same executive functioning tasks. More specifically, they found that bilinguals utilise overlapping regions of language control and executive control, when performing a switching task independently of the trial type, while monolinguals recruit parts of the same networks, depending on the type of trial (verbal or non-verbal) (see Pliatsikas and Luk, 2016 for review).

\subsection{Healthy brains in older populations}

Bilingualism effects seemingly manifest more profoundly in older age, with older (usually tested at ages 60 and above) neurotypical bilinguals performing better than comparable monolinguals in tasks associated with executive control (Baum and Titone, 2014; Bialystok et al., 2014b, 2004). Number of languages spoken also predicts higher cognitive screening test scores, with those individuals speaking a higher number of languages exhibiting better preserved cognitive abilities longitudinally over 12 years of testing (Kavé et al., 2008). 
Turning to the neuroanatomy of the brain, evidence from older populations echoes the results found in young adult populations. Bilingualism in older adults is linked to higher GM volume in cortical areas and subcortical structures of the brain linked to language learning and bilingual language control (Abutalebi et al., 2015). More specifically, examples of the areas affected by bilingualism include dorsolateral prefrontal cortex (PFC), an area implicated in language control and conflict resolution, which is better preserved in ageing bilinguals. The ACC is also found to have increased GM volume in ageing bilinguals (Abutalebi et al., 2012) as is anterior temporal pole. Although the latter is not implicated in executive control per se, it does relate to language in serving as a conceptual hub where semantic information is stored (Abutalebi et al., 2014). This shows that not only areas directly involved in bilingual language control and executive control, but also brain areas associated with aspects of language processing are affected by bilingualism. Effects extend to WM structures; just like their younger counterparts, older bilinguals exhibit greater integrity in their interconnecting WM tracts. For example, this has been found in the $\mathrm{CC}$, superior longitudinal fasciculi bilaterally and right IFOF (Luk et al., 2011). Mirroring these results, Gold et al. (2013) found better WM integrity in the ILF/IFOF, fornix and parts of CC. Anderson and colleagues (2018) also found similar group differences, namely, bilinguals exhibiting higher integrity in parts of the CC, left superior temporal longitudinal fasciculus and anterior IFOF, but also in the right external capsule and bilateral superior posterior corona radiata. These differences have been interpreted as potential neuroprotective effects in healthy older populations because they largely represent better preservation and/or reserve in combating the processes of natural cognitive decline. To summarise, the areas that have been shown to differ between healthy ageing bilingual and monolingual populations underlie executive control and bilingual language control (see Grant et al., 2014, for a review). 


\subsection{Bilingual brain in ageing clinical populations: Alzheimer's Disease and Mild Cognitive}

Impairment

The reporting of suggested neuroprotective effects of bilingualism in older age prompted some researchers to investigate whether and how this neuroprotection interacts with pathological neurodegeneration caused by progressive diseases (Gold et al., 2013a; Schweizer et al., 2012). This has been particularly true for Alzheimer's Disease (AD), which, as the most prevalent form of dementia globally (Ferri et al., 2005), was the first disease to be investigated. Before reviewing the evidence on bilingualism an $\mathrm{AD}$, it is useful to review the mechanism underlying the condition.

According to the Amyloid Cascade Hypothesis (Karran et al., 2011), the dominant theory in $\mathrm{AD}$ research, in this type of dementia the brain is subject to aggregation of Amyloidbeta $(\mathrm{A} \beta)$ protein, and formation of cortical amyloid plaques. The varying distribution of this pathology results in presentation of different AD subtypes. The above leads to eventual progressive synaptic degeneration, hippocampal neuron loss and overall cerebral atrophy via formation of paired helical filaments of tau protein. However, the exact mechanism of how aggregation of $A \beta$ protein and tauopathy leads to neurodegeneration is not yet well understood (Scheltens et al., 2016; Swerdlow, 2007). Global cortical atrophy is characteristic to AD with neurodegeneration of other brain areas also present. Areas and structures affected by the disease include the hippocampal formation and medial temporal lobe, including the entorhinal cortex. In addition to that, other structures are also subject to deterioration. This includes development of WM lesions and reduced integrity of a wide array of WM tracts and structures, including, but not limited to, the CC, fronto-occipital fasciculus, ILF, and fornix. Subcortical GM structures such as basal forebrain, basal ganglia, are affected too (for a review see Pini et al., 2016). Clinically, typical AD results in gradual loss of episodic memory and deterioration of wider cognitive functions (Mucke, 2009). 
The concept of MCI has only been introduced in the last few decades. The most common type, amnestic MCI, can be characterised as a state of memory impairment worse than what would be expected for a given age and educational level, but not meeting criteria for a mild $\mathrm{AD}$ diagnosis. It can be considered as a transitional state between healthy ageing and $\mathrm{AD}$, although MCI does not always advance to $\mathrm{AD}$ (however, people with $\mathrm{MCI}$ are at greater risk of developing the disease) (Petersen et al., 1999). People with MCI do not have adversely affected daily functioning, although it might take longer than before the onset of symptoms to perform certain tasks. The main symptoms include changes in cognitive performance, for example, increased forgetfulness (Petersen, 2016).

The cognitive effects of bilingualism observed in healthy populations, as discussed above, seemingly translate into health-related implications in clinical contexts. Most notably, there is an increasing body of evidence suggesting that bilingualism is a factor that contributes to delaying the onset of $\mathrm{AD}$ symptoms by $4-5$ years in bilingual individuals when compared to education- and age-matched monolinguals (Alladi et al., 2013; Bialystok et al., 2007; Woumans et al., 2015; but see e.g., Zahodne et al., 2014; for a review see Guzmán-Vélez and Tranel, 2015, or Calvo et al., 2016). Mirroring the evidence for delayed onset of AD symptoms in bilingual individuals, there is also some support for later diagnosis of MCI in bilinguals (Bialystok et al., 2014a; Ossher et al., 2013).

While this research suggests bilingualism to be a factor that delays the onset of clinical dementia symptoms (i.e., cognition and behaviour), little is known about the neurological effects of bilingualism in ageing clinical populations. Emerging literature has shown AD bilinguals to exhibit better cognitive functioning at higher levels of dementia-related brain atrophy, suggesting a higher cognitive reserve, although this was not found in a MCI bilingual patient group (Duncan et al., 2018). In this study, both AD and MCI bi- or multilingual patients exhibited higher cortical thickness than their monolingual counterparts in areas related to 
language control and executive control (including the IFG, supramarginal gyri, and anterior temporal gyri bilaterally, left medial superior frontal gyrus, right ventromedial PFC, left IPL, and the cerebellum), suggesting a protective neural reserve effect in these areas. This result conforms to the observed trend in the literature where evidence for neural reserve (i.e., increased structural support) is found in healthy populations, while evidence for cognitive reserve (i.e., cognitive functioning at levels better than expected for the observed amount of sustained brain damage) can be seen in cases where the structural integrity of the brain has been compromised by neurodegenerative disease. This may serve as an indication for presence of neural reserve in MCI, where the deterioration of the brain is not severe enough for effects of cognitive reserve to be observable.

There is also a small but emerging body of literature examining other aspects of brain biology, such as metabolism, with respect to the effects of bilingualism. In this literature, and in line with the cognitive reserve hypothesis, bilingual $\mathrm{AD}$ and $\mathrm{MCI}$ sufferers show significantly reduced glucose metabolism and uptake in frontal regions (e.g., right IFG), temporoparietal brain areas (e.g., left inferior parietal lobe, medial temporal gyrus) and cerebellum than monolingual individuals while exhibiting similar cognitive performance to them (Kowoll et al., 2016). Bilingual AD patients also exhibit resting state hypometabolism, a measure indicating lower synaptic density and activity in frontal, temporal, parietal regions, and the cerebellum, while at the same time performing better than monolinguals in verbal memory and visuospatial tasks, thus supporting the cognitive reserve hypothesis (Perani et al., 2017). And finally, although examining cognitively healthy, and not clinical, populations, Estanga et al., (2017) found lower cerebrospinal fluid (CSF) total-tau (t-tau) concentration in bilingual middle-aged individuals than monolingual individuals. CSF t-tau levels serve as a biomarker for neurodegeneration (Blennow et al., 2001); this study is the first to show a more favourable CSF AD-biomarker profile associated with bilingualism and might show that 
bilingualism not only protects the brain structures and function, but also works in a way to reduce the probability of tau pathology development.

\subsection{Interim Summary: The motivational links}

The above subsections (2.1.-2.3.) provide links between behavioural and biological clinical effects of bilingualism overall, and especially how they interact with AD and MCI. If bilingualism has such effects, then we should ask if it has comparable effects in other progressive diseases which affect components of the executive control network. In fact, we might turn that question around and ponder how it could not, if the explanations/links offered to date are on the right track. Extending the question of bilingual effects to neurodegeneration more generally, thus, has theoretical importance beyond the obvious practical health benefits. Indeed, if previously observed effects are bona fide and replicable, then we should see similar effects in other disorders where neurodegeneration is targeting cortical and subcortical GM regions and WM tracts protected by bilingualism and the associated executive control demands. If not, this would provide motivation to rethink claims at the most basic conceptual and theoretical levels. If bilingualism offers provisions for cognitive and neural reserves with knock-on ameliorative effects in $\mathrm{AD}$ and $\mathrm{MCI}$, there is no reason a priori that there should be no effect for other neurodegenerative diseases. Unless, of course, there are independent reasons why such reserves could be nullified. For example, in dementia with Lewy bodies (related to Parkinson's) cognitive reserve related to executive functions might have less benefit because these are implicated less in this type of dementia (see Alladi et al., 2013, for empirical support). That said, neural reserve could still have an effect on, for example, PD given the prime locus of impairment - the basal ganglia - which, beyond motor control, are also implicated in bilingual language control and are already reported to be 'enhanced' by bilingualism (Burgaleta et al., 2016; Hervais-Adelman et al., 2018; Pliatsikas et al., 2017) . At present, however, a 
critical-mass literature is ostensibly limited to the AD and MCI pathology. Such is understandable as $\mathrm{AD}$ is the most common type of dementia, with patient populations easier to access. But this should not limit inquiry in other neurodegenerative disorders, precisely because there are shared aspects of neuropathology and the physiological mechanisms between various diseases.

Although there is a wide range of progressive and non-progressive neurological conditions that result in cognitive impairment and loss of neural tissue, the available literature on these disorders is mostly focused on the effects that age- or disease-related neurodegeneration has on one's language ability and associated executive control, and not the effects bilingualism per se may have on the progression of and/or onset of symptoms related to neurodegeneration. The last relevant comprehensive review relating to bilingualism (Paradis, 2008) was published more than a decade ago, but even so the focus then was on understanding how neurological disorders impair language processing in bilinguals, not on the effects bilingualism might have on cognition and brain structure. Given the now proposed neuroprotective effects of bilingualism in ageing (virtually non-existent 12 years ago), it is important and timely to re-examine the literature through this new lens.

\section{Beyond dementia of Alzheimer type: Evidence supporting (or not) bilingualism as a protective factor in neurodegenerative disorders?}

Even in the absence of research specifically designed to ask and answer questions related to bilingualism links in neurodegeneration par excellence, it follows from the evidence discussed above that bilingualism could have an impact on the surface manifestations of neurological disorders in general (i.e. more than in AD). Despite the dearth of research focused on this question, there are indeed some very promising results to which we now turn. 
Although available studies are limited to a small subset of progressive neurodegenerative disorders, we assemble herein the available literature and evidence on the effects of bilingualism on a range of neurodegenerative diseases. We discuss a disease per subsection and review the literature looking at established and potential effects of bilingualism on clinical outcomes for each condition. We cover three progressive neurodegenerative disorders, other than AD and MCI, namely Huntington's disease, Parkinson's disease, and Multiple Sclerosis. While all three disorders are primarily known as motor disorders, they are also accompanied with cognitive consequences. Crucially, there is (partial) overlap in terms of what structures and brain areas are targeted by each disease. Taken together, we will conclude that there are very encouraging reasons to forge forward with a specific research agenda that seeks to better understand the neurocognitive effects bilingualism can have on degenerative disorders more generally.

\subsection{Huntington's Disease}

Huntington's Disease (HD) is an inherited, genetic neurodegenerative disorder with (typical) onset of symptom expression in middle age (Davies et al., 1997). The genetic cause of $\mathrm{HD}$ is a mutation in the huntingtin gene resulting in an abnormal number of repetitions of cytosine-adenosine-guanine bases (CAG). Those with more than 35 CAG repetitions will experience an onset of HD at roughly 45 years of age. The number of CAG sequence repetitions correlate with earlier onset and severity of HD symptoms as well as associated changes in the brain, primarily in the striatal areas (Kassubek et al., 2004). In general, the progression of HD can be divided into three stages - preclinical, prodromal and symptomatic. In the preclinical stages, carriers of the mutant huntingtin gene do not behaviourally differ from healthy individuals. Prodromal stage implies some deterioration in patients' cognition; however, this does not impede everyday functioning and in itself is not sufficient for establishing a HD 
diagnosis. The symptomatic stage is characterised by a HD diagnosis based on presence of motor impairment (Ross and Tabrizi, 2011).

Behaviourally HD usually manifests as a progressive motor disorder accompanied by cognitive and neuropsychiatric deficits. The primary motor symptoms in HD are chorea (involuntary jerky movements), bradykinesia (slowness of movement) and rigidity, resulting in impaired gait, dysarthria and dysphagia (Ross et al., 2014). Cognitive deficits manifest as executive function deficiency, impaired attention, episodic memory, and working memory (see Papoutsi et al., 2014, for review). Neuropsychiatric symptoms include emotional disorders, such as depression, irritability, and personality changes. In rare cases HD patients experience delusions, hallucinations, and compulsive behaviour (Craufurd et al., 2001). To this day, there is no pharmacological cure or treatment available for HD (Ross et al., 2014).

\subsubsection{The neural basis of cognitive impairments in HD: Links to Bilingualism Effects.}

\section{Subcortical grey matter}

Although there is a certain amount of heterogeneity in the clinical phenotype between individuals with $\mathrm{HD}$, at the population-level there is consistency between clinical symptoms and patterns of cortical and subcortical atrophy and functioning (Coppen et al., 2018; Rosas et al., 2008; Scahill et al., 2013). Importantly, there is considerable overlap between regions displaying neural reserve in bilingualism and atrophy in HD and the associated cognitive functions/symptoms of these areas. This raises the possibility of the bilingual experience as a mechanism for impacting the expression and progression of HD.

Primarily and universally, HD is associated with decline in the striatum (caudate nucleus, putamen and globus pallidus). Additionally to striatal decline, and with greater individual variation, other subcortical GM structures, such as the thalamus, hypothalamus, and substantia nigra are also affected by the disease (see Walker, 2007, for an overview). 
Degeneration and dysfunction in these regions have been identified using a range of measures. Volumetric GM reductions have been observed in the striatum and thalamus (Aylward et al., 2011; Kassubek et al., 2005); the same structures also show changes in their structural integrity as evidenced by increased mean diffusivity and fractional anisotropy measures (Douaud et al., 2009). Diminished striatal functioning has been inferred through reduced glucose metabolism (Ciarmiello et al., 2006). Structural changes can be observed in presymptomatic as well as symptomatic HD patients (Liu et al., 2016) and increasing decline can be longitudinally observed as the disease progresses (Aylward et al., 2011).

The integrity of these subcortical structures has been found to correlate with the severity of behavioural symptoms in HD including, and of particular interest to this review, executive functioning. Atrophy of the thalamus bilaterally was found to co-vary with cognitive performance as measured by lower scores in letter fluency, digit symbol and Stroop tasks, signalling reduced inhibition and cognitive control (Kassubek et al., 2005). Alterations in putamen and caudate nucleus volume and local dopaminergic metabolism correlates with visuospatial abilities (Ray Complex Figure, copy and WAIS-R, Block Design test), perceptual speed (WAIS-R, Digit Symbol test), reasoning (WAIS-R, Picture Arrangement test) and verbal fluency (Controlled Oral Word Association Test) (Backman et al,1997). While there is limited functional imaging data available from HD samples, the bilateral putamen has been shown to be hypoactive during tasks with high working memory load in pre-HD individuals (Wolf et al., 2008). The same study showed that pre-HD individuals also exhibit reduced functional connectivity in networks within the left DLPFC and the left superior parietal cortex, including bilateral putamen. From here, lesser activation within the left putamen accounts for variation on behavioural measures in the Unified Huntington's Disease Rating Scale (UHDRS). 


\subsubsection{White matter}

Individuals with HD are also vulnerable to WM degeneration. Global WM volume reductions can be observed early in presymptomatic HD gene carriers when compared to healthy individuals (Aylward et al., 2011), and WM atrophy can precede GM atrophy (Ciarmiello et al., 2006). The CC is particularly vulnerable. Reduced CC integrity has been observed through increased mean diffusivity (Bohanna et al., 2011) and reduced fractional anisotropy, suggesting demyelination or degeneration of WM axons (Della Nave et al., 2010; Rosas et al., 2010). These findings align with observations of reduced myelin content in the $\mathrm{CC}$ using macromolecular proton fraction (MMPF) measures (Bourbon-Teles et al., 2019). Beyond the $\mathrm{CC}$, there is evidence of reduced integrity in numerous WM structures such as frontostriatal tracts, internal capsule and subcortical tracts, including IFOF and ILF (Di Paola et al., 2012; Rosas et al., 2006).

WM integrity has been related to motor and wider cognitive functions. Of particular interest, callosal degeneration has been linked to performance on cognitive and functional components of Unified Huntington's Disease Rating Scale (UHDRS) (measuring overall severity of the disease), including Symbol Digit Modalities Test (attention, perceptual speed), Verbal fluency (updating, lexical access speed), Stroop tasks (Rosas et al., 2010) and general cognitive/executive impairment (excluding working memory) (Bohanna et al., 2011; BourbonTeles et al., 2019). Performance on the Stroop task has also been related to the structure of bilateral IFOF and sub-regions of the internal capsule (Della Nave et al., 2010; Rosas et al., 2006).

\subsubsection{Cortical grey matter}

Unlike subcortical GM and WM, no selective significant atrophy can be observed longitudinally in cortical GM in prodromal HD patients (Aylward et al., 2011). There have 
even been reports of increased cerebral GM in preclinical HD patients when compared to matched controls suggesting a compensatory mechanism is at play (Paulsen et al., 2006). Although cortical thinning in $\mathrm{HD}$ is heterogeneous, it has been related to various neuropsychiatric and executive behaviours. For example, the cingulate cortex is reported to be approximately $10 \%$ smaller in early symptomatic HD patients compared to healthy controls, and this has been related to impairments in visual memory (Hobbs et al., 2011). Cingulate cortex has also been shown to exhibit hypometabolism in HD (Eidelberg and Surmeier, 2011). Reductions in frontal cortex volume has been related to impairments in switching (Trail Making Test-B; Wisconsin Card Sorting Task) and episodic memory (Rey-Osterrieth's Complex Figure-memory; Word Recall task) (Backman et al., 1997). Reduced glucose metabolism has also been observed in frontal areas as well as temporal areas (Ciarmiello et al., 2006) and reduced activity from the medial frontal gyrus, bilateral ACC, superior frontal gyrus and middle frontal gyrus was observed in HD participants while performing a Go/Nogo task (measuring inhibition) (Beste et al., 2008).

\subsubsection{Evidence for general cognitive/neural reserve in $H D$}

Bilingualism can only impact the progression of HD if the (progression of the) disease can be ameliorated by environmental factors that have neural consequences. Recall that, at present, there is no treatment or cure for HD (Ross et al., 2014). However, there are reasons to believe that brain (i.e., cognitive and neural) reserve mechanisms might reduce the severity or even delay onset of HD symptoms. There is now evidence for the role of environmental factors that slow down the expression of motor and cognitive HD symptoms in animal models, implicating neural reserve and/or cognitive reserve as potential modulators of the clinical progression of HD (see Nithianantharajah and Hannan, 2011, for a review). In humans, it has been shown that HD individuals with 'cognitively active' histories (e.g. engagement with 
higher education, cognitively challenging professional activities) have less severe clinical profiles (Lopez-Sendon et al., 2011), experience onset of HD symptoms 4.6 years later than those leading passive lifestyles (Trembath et al., 2010) and perform better on working memory, inhibition and switching executive function measures (Garcia-Gorro et al., 2019). This is the case even when the genetic predisposition to HD severity, namely, number of CAG repeats, is controlled for (Chao et al., 2017). At a neural level this cognitive engagements results in differences in functional connectivity between the bilateral ACC and angular gyrus (GarciaGorro et al., 2019) alongside a reduced atrophy rate in the bilateral caudate nucleus and putamen (Bonner-Jackson et al., 2013).

Behavioural motor and cognitive rehabilitation techniques in HD have been shown to increase the volume of right caudate nucleus and the DLPFC bilaterally. Increased GM volume has been observed in superior thalami, left inferior temporal pole, right subcallosal cortex, and parasagittal primary motor areas. These volumetric increases in GM have been correlated to significant improvements in verbal learning and memory (Hopkins Verbal Learning Test-R) (Cruickshank et al., 2015), indicating that neuroplasticity/reserve mechanisms can be behaviourally modulated in HD. As a result, there have been calls to consider these possible reserve mechanisms and implement large scale studies on how cognitive and/or motor interventions might ameliorate the symptoms via the reserve mechanism (Andrews et al., 2015).

\subsubsection{HD and bilingualism}

Overall, there is close alignment between the atrophy patterns related to executive function impairments in HD and the regions where neural reserve is observed in bilingualism, including several subcortical structures, such as the caudate nucleus, putamen, thalamus, and WM tracts, such as the IFOF, ILF and CC. This raises the possibility that bilingualism may 
have a similar neuroprotective role in HD to that identified in AD given that some of the neural substrates of the conditions are shared. The cognitive impairments in HD associated with these regions are linked to the cognitive functions that are hypothesised to be enhanced through active bilingual experience.

Although the literature directly examining this hypothesis is scarce, a recent study found that inhibition (as measured by a cross-lingual Stroop task) was better preserved than language skills in bilingual individuals with HD (Calabria et al., 2018b), potentially indicating cognitive reserve in some aspects of executive functioning. Moving from behaviour to effects of bilingualism on brain structure and function in HD specifically, Martínez-Horta and colleagues (2018) recently reported active bilingualism to be associated with increased GM volume in the right IFG. While they did not explore for any effects on WM or subcortical GM, they also used Positron Emission Tomography relative standardised uptake value (SUVr) and reported significantly higher brain glucose metabolism in various clusters across the brain, including the dorsal ACC, the ventromedial orbital PFC, the insula, the superior orbital PFC, the left IFG and the right inferior temporal gyrus. These findings indicate better preserved brain function and structural integrity in early and mild HD: increased metabolism in mostly frontotemporal areas of the brain, all known to be affected by HD, and increased volume of the IFG serves as evidence for build-up of neural reserve in the presence of lifelong bilingualism.

It is important to note that neural changes in HD gene carriers can be observed well before any clinical symptoms manifest in the prodromal stage. Changes in the brain can be detected 20 years before onset of clinical symptoms, while mild changes in behaviour can be observed as early as 10 years before diagnosis (Papoutsi et al., 2014). Even at baseline and equal MMSE scores, presymptomatic HD patients show reduced volumes of striatum, including caudate nucleus, globus pallidus and putamen volumes (Majid et al., 2011). This indicates cognitive reserve at work in HD. If there is an underlying and clinically silent atrophy 
and deterioration of the brain for years before manifestation of any symptoms, there should be a compensatory mechanism, the efficiency of which may depend on various environmental factors. As such, there may be an opportunity to extend the presymptomatic latent period through the neural and cognitive reserve brought about by the bilingual experience.

\subsection{Parkinson's Disease}

Parkinson's Disease (PD) is another neurodegenerative disease primarily associated with motor impairment. It is, however, often accompanied by a number of non-motor symptoms. Concomitant cognitive dysfunction can occur in PD, particularly as the disease progresses, and is the most common non-motor symptom (Aarsland et al., 2017). PD is neuropathologically characterised by degeneration of dopaminergic neurons in substantia nigra and subsequent depletion of dopamine in the basal ganglia (Lotharius and Brundin, 2002). This, accompanied with Lewy body presence, clinically manifests as motor impairments such as muscular rigidity, bradykinesia (slowness of movement) and rest tremor (for a review, see Jankovic (2008). There is variability in the expression of cognitive impairment in PD, ranging from healthy cognitive ageing to mild cognitive impairment (PD-MCI) to dementia (PDD). Development of MCI and dementia in PD is associated with cortical deposits of Amyloid- $\beta$ plaques and other factors typical of development of AD (Petrou et al., 2015). Cognitive impairment in PD can manifest as impairment in executive functioning (Kudlicka et al., 2011), memory and visuospatial abilities (Watson and Leverenz, 2010), deteriorated social cognition (Kawamura and Koyama, 2007), psychosis (Papapetropoulos and Mash, 2005), and depression (Reijnders et al., 2008). A recent meta-analysis has shown that even in PD patients without dementia there are comprehensive deficits in attention, working memory, visuospatial and verbal memory abilities, when compared to healthy controls (Curtis et al., 2019). Like dementia of the Alzheimer's type, the exact cause of PD is unknown, but it is thought to develop as a 
result of a combination of genetic and environmental factors. This makes PD a heterogeneous disorder with commonalities to both $\mathrm{AD}$ and HD. Similarly, there are no curative pharmacological treatments for the underlying neurodegenerative process in PD. Available treatments only reduce symptoms (Kalia and Lang, 2015). There are numerous reviews summarising the structural and functional neurobiological symptoms in PD and the associated symptoms (e.g., Chaudhuri et al., 2006; Kalia and Lang, 2015). Below, we briefly identify key structural and functional characteristics of the disease, particularly with respect to structures relevant to the neurobiology of bilingualism.

\subsubsection{The neural basis of cognitive impairments in PD. Subcortical grey matter}

Subcortical GM structures have mostly been linked to motor symptoms in PD. To further tease apart individual involvement of specific components within the subcortical structures on motor function, a recent study (Li et al., 2018) looked at a large sample size $(n=392)$ of PD patients drawn from a PD MRI scan repository and correlated them to Universal Parkinson's Disease Rating Scale (UPDRS) scores, measuring severity of PD-related impairment and disability (Goetz et al., 2008). The total MDS-UPDRS III (motor) score was significantly negatively correlated bilaterally with GM density in the putamen and caudate nucleus. Lower anterior striatal GM density was significantly associated with higher rigidity subscores, whereas left-sided anterior striatal and precentral cortical GM reduction were correlated with severity of axial symptoms, such as postural instability and trunk posture alterations. No significant morphometric associations were demonstrated for tremor subscores. Smaller bilateral caudate nucleus volumes were associated with severity freezing of gait symptoms in PD (Herman et al., 2014).

While PD motor symptoms are associated with basal ganglia impairment, relatively less is known about the neurological changes and mechanisms underlying wider cognitive 
decline in PD (Aarsland et al., 2017). To some extent basal ganglia also seem to mediate cognitive outcomes in PD. Subcortical and basal ganglia lesions are concomitant with executive function deficits in PD patients (Ardila et al., 2019). In a longitudinal study, PD patients showed significant volumetric reductions across 18 months between visits in thalamus, caudate nucleus, putamen, hippocampus, amygdala, nucleus accumbens (Vasconcellos et al., 2018). These reductions were accompanied by worse outcomes in attention, executive functioning, visuospatial processing measures and overall cognitive decline, although it is unclear whether neuropathology directly predicts cognitive symptoms (Aarsland et al., 2017).

There is evidence from functional brain MRI scans implicating specific subcortical structures and certain cortical areas to executive function decline in PD (Gawrys et al., 2014). This study found the neural substrate of executive dysfunctions in PD to be found within the fronto-parietal-striatal areas of the brain. In more detail, lower activation in right central opercular cortex, left putamen, and left intracalcarine cortex has been linked with decreased inhibition, and lower activation in right IFG, right caudate nucleus and right putamen has been linked with lower task switching ability. However, lower working memory performance has been associated with increased activation in the right lingual gyrus.

\subsubsection{White matter}

Structural and functional impairment of WM precedes deterioration of GM in PD. Reduced structural integrity (decreased FA) in CC is associated with reduced visuoconstruction abilities (Auning et al., 2014). Global cognition in PD patients (measured by MMSE scores) significantly correlates with FA measures in the parietal WM regions bilaterally (Hattori et al., 2012).

As with HD, CC shows reductions in both structural integrity and volume in individuals with PD. Reductions in WM integrity of CC have been associated with decreased performance 
in a variety of executive functioning domains, such as attention, working memory, language performance and visuospatial processing (Bledsoe et al., 2018). Overall decline of WM volume has been shown to predict cognitive decline and conversion to MCI in cognitively asymptomatic PD patients (Wen et al., 2015). These results are mirrored in a volumetric study of the $\mathrm{CC}$, where reduced $\mathrm{CC}$ volume was found in the mid-anterior and central regions in PD in comparison to healthy controls. Significant differences were observed within the PD cohort with total CC volume significantly shrinking as cognitive symptoms progressively worsened from PD with no cognitive impairment to PD-MCI to, eventually, PDD. Regional callosal atrophy predicted cognitive domain performance such that central volume was associated with the attention and working memory domains; mid-posterior volume with executive function, language, and memory domains; and posterior volume with memory and visuospatial domains (Goldman et al., 2017).

Apart from WM integrity deficits in the CC, other tracts have also been implicated in PD. These structures include frontal and parietal tracts, including the superior and inferior longitudinal fasciculi (SLF and ILF) and the IFOF (Duncan et al., 2016). WM deficiencies have also been explicitly linked to development of PD-MCI. A longitudinal study found that among a cohort of comparable PD patients at baseline, those who develop MCI have greater WM reductions over time when compared to patients who remained cognitively healthy. However, longitudinal changes in GM volume does not predict development of MCI in PD patients in the same way WM atrophy does (Wen et al., 2015).

\subsubsection{Cortical grey matter}

Similar to HD, there is considerable heterogeneity in cortical GM atrophy in PD, which may account for varied clinical cognitive profiles among patients. In general, cognitive deficits and development of dementia are associated with widespread cortical thinning. Volumetric 
reductions are found rather globally, in frontal, parietal, temporal lobes, and the parahippocampal and cingulate cortices (for detailed reviews see Hall and Lewis, 2019; Yousaf et al., 2017). Generally, progressive cortical GM atrophy can be observed as the disease develops and is associated with both motor symptom severity and global cognitive impairment (Wilson et al., 2019). Some bilateral prefrontal atrophy can be observed in cognitively healthy PD patients. While cognitive impairment in this case is not sufficiently severe for a MCI diagnosis, it has been expressed as poorer attention (Brück et al., 2004). Moreover, frontal, temporal, and parietal GM thinning have been associated with reduced semantic fluency and executive function performance in PD patients (Duncan et al., 2016).

When compared with healthy controls, non-demented PD patients showed significant reduction of cortical GM primarily in the frontal and parieto-occipital regions and reduced performance in fine motor speed and set-shifting (Lee et al., 2013). Patients that have converted to the next stage of the disease and diagnosed with PD-MCI exhibit greater cortical volume loss across occipital, temporal, parietal, and frontal cortices (for review see Aarsland et al., 2017). Longitudinally, there is a faster rate of cortical thinning in PD-MCI, when compared to PD with healthy cognition, in the temporal lobe, supplementary motor area and medial occipital lobe (Hanganu et al., 2014), as well as in frontal and temporo-parietal cortices (Mak et al., 2015). This indicates these areas to be most involved in supporting cognitive functioning in PD. Note, not all of these areas are overlapping with the set of areas associated with changes caused by the bilingual experience and have been included for completeness. Another measure, GM density, is lower even in cognitively healthy PD patients, when compared to healthy control groups scattered across numerous frontal, parietal, temporal and occipital areas, including left anterior cingulate gyrus, middle and inferior frontal gyrus, inferior parietal gyrus, and bilateral insula. These reductions are even more severe in PD-MCI patients (Chen et al., 2016). With regards to specific cognitive deficits, PD-MCI patients exhibit poorer performance 
in executive functions (phonemic fluency, processing speed), immediate verbal memory and visual recognition memory in comparison with PD patients with healthy cognition (Lee et al., 2013).

Severity of dementia in PDD positively correlated with GM reductions in the medial temporal lobe (Pan et al., 2013). Another study found no difference between cortical thickness in PD patients and healthy controls, however, the surface area of the cortex was larger in PD patients (Jubault et al., 2011). This indicates increased folding at the cortical level and the authors hypothesised that this may be due to shrinkage of underlying WM giving rise to deeper sulci and thus leading to increased cortical surface area.

To summarise, cognitive dysfunction and dementia in PD is linked to a widespread atrophy across the cortical GM. The more severe the dysfunction, the greater and more scattered the loss of cortical GM, especially in frontal and temporoparietal cortices.

\subsubsection{Evidence for general cognitive/neural reserve in $P D$}

There is evidence that the behavioural manifestation of PD is modulated by the degree of cognitive and neural reserve in individuals (e.g., Armstrong et al., 2012). From potential contributor factors to cognitive reserve, education is the only proxy that has been systematically studied in PD. Better cognitive performance in highly educated individuals with PD (for a review see Hindle et al., 2014) and higher educational attainment predicts better maintenance of global cognitive performance once levels of cortical A $\beta$ pathology have been controlled for (Lucero et al., 2015). Higher estimated premorbid IQ and years of education (both widely used proxies for cognitive reserve) are associated with reduced likelihood of progressing from PD with no cognitive impairment to PD-MCI (Armstrong et al., 2012; Koerts et al., 2013). The impact of education or 'cognitive lifestyle' on executive functioning specifically is somewhat mixed with one study identifying a positive effect on executive neuropsychological tests (e.g. 
WAIS similarities subtest and Digit Span Forward (Guzzetti et al., 2019) while another found no relationship (Hindle et al. 2017). Perhaps unexpectedly, a link has also been identified between cognitive reserve and motor outcomes. Low educational attainment and low scores in the Cognitive Reserve Index questionnaire (CRIq) - a questionnaire that permits a quantification of a Cognitive Reserve Index, by taking into account education, working activities and leisure activities — are associated with more severe motor impairment in PD after controlling for age and disease duration (Guzzetti et al., 2019; Kotagal et al., 2015).

A recent review of cognitive training studies in PD suggests a general trend for cognitive training attenuating cognitive decline in individuals with PD (Leung et al., 2015). While the literature is ostensibly small (review of 7 studies), improvements following cognitive training were noted across multiple domains, including overall cognition, working memory, processing speed and executive functioning. The authors argue that the current small body of literature promising and call for future studies exploring and establishing standards for cognitive training in PD populations. In line with the main theme of the review by Leung and colleagues, if behavioural cognitive training can affect clinical outcomes in PD, there are reasons to believe that so may the experience of bilingualism. It is reasonable to assume that bilingualism, and the associated cognitive load of constantly managing more than one language, can be considered a form of cognitive training in itself that might offer similar clinical effects in the long run.

\subsubsection{PD and bilingualism}

Similar to HD, there is an overlap between the neural structures displaying neural reserve in bilingualism and the structures associated with cognitive and motor decline in PD, in particularly in subcortical structures such as the basal ganglia, WM tracts such as the CC, IFL and IFOF. Taken together with the evidence for the impact of cognitive reserve on the 
expression of PD, it indicates that bilingualism may have a neuroprotective role in PD. To date only a single study has addressed this hypothesis, where a group of English-Welsh bilinguals with PD displayed no difference on neuropsychological assessments of mental generativity, working memory, inhibition and switching when compared to a group of monolingual English speakers with PD (Hindle et al., 2015). No structural brain imaging data were available for these participants and, therefore, it cannot be ruled out that the bilingual speakers were performing similarly to the monolingual speakers while having greater neural atrophy/dysfunction (i.e. displaying increased cognitive reserve). Hindle and colleagues also did not explicitly state whether cognitive impairment was present in this participant cohort and the mean MMSE scores were near ceiling with small standard deviations, indicating that most participants were cognitively healthy. As such, there may have been insufficient variation in this study to observe the impact of bilingualism.

In sum, there seems to be an overlap in the patterns of neurodegeneration in $\mathrm{AD}, \mathrm{HD}$, and PD and there are shared features in associated behavioural changes. Similarly, there is evidence for cognitive reserve playing a role in attenuating symptoms, where it correlates to predicting smaller cognitive decline, executive function impairment and severity of motor symptoms in PD. Given that bilingualism is an established cognitive reserve contributor, attention from the scientific community to empirically evaluate the potential effects it may have on PD patients is needed.

\subsection{Multiple Sclerosis}

Multiple Sclerosis (MS) is an autoimmune disease that has traditionally been associated with progressive inflammatory neurodegeneration of WM within the brain and spinal cord. The characteristic neuropathology includes axonal and neuronal loss, demyelination, and astrocytic gliosis (non-specific changes in astroglia, indicative of central nervous system pathology). This 
occurs secondary to inflammation following an autoimmune response specific to the central nervous system (Lassmann et al., 2012; Thompson et al., 2018). MS targets the insulating myelin on axons in the central nervous system, destroying them to varying degrees. As the sum total of these smaller lesions compounds, this demyelination and neurodegeneration leads to $0.5 \%-1.35 \%$ total brain volumetric loss annually (De Stefano et al., 2014) and widespread lesions within the spinal cord. These lesions are diffuse and can be found in both neural GM and WM. The disorder is understood to be caused by a combination of genetic, environmental, and lifestyle factors (Olsson et al., 2016). Onset of MS symptoms happens much earlier in life than it typically does in HD or PD, commonly in early adulthood. Clinically, early MS is usually expressed via acute episodes of neurological deficits, known as relapses. The symptoms experienced during relapses are specific to the area of the central nervous system affected and the extent of neurodegeneration (Thompson et al., 2018). Deficits span motor, cognitive, and neuropsychiatric domains which may manifest independently of each other or in any other cooccurring combination (Feinstein et al., 2013). As a result, the symptom profile in MS is heterogeneous.

There are four clinical courses of the disease, based on the rate of disease progression. Relapsing-remitting MS (RRMS) is characterised by sudden intensification of symptoms followed by periods of remission. Primary progressive MS (PPMS), secondary progressive MS (SPMS), and progressive-relapsing MS (PRMS) are defined by their continuous nature. In PPMS and SPMS the patients do not experience remission as the neural deterioration and symptoms become gradually worse. Most RRMS patients will develop SPMS as the disease progresses, whereas PPMS patients experience the progressive nature of MS from the onset. In PRMS there are no periods of remission or improvements between acute relapses as the symptoms get gradually worse over time (Chiaravalloti and DeLuca, 2008). Although statistics suggest a very high likelihood of RRMS patients developing SPMS ( 80\%), there are 
indications that, if the disease is actively managed, only $11.3 \%$ of patients transition from RR to SP MS stages within a ten-year follow-up (Cree et al., 2016). In other words, evidence suggests that progression can be ameliorated with taking appropriate measures. At the moment, pharmaceutical treatments have been developed for relapsing-remitting stages of the disease and those target neuroinflammation, not neurodegeneration per se. This is to reduce the severity of new demyelination episodes and relapses (Lassmann et al., 2012). Non-pharmacological treatments, such as exercise, physiotherapy, cognitive behavioural therapy, occupational therapy are also used (Thompson et al., 2018). There are no current pharmacological treatments for later, progressive stages of MS.

Among other symptoms, cognitive impairment has been recognised as a core component of MS, occurring in approximately 40-65\% of patients (Amato et al., 2006; Julian, 2011). Where present, cognitive symptoms develop early in the disease. There is individual variability in the expression of the symptoms, depending on the MS subtype (Sumowski et al., 2018). Progressive variants of MS result in more severe cognitive deficits when compared to RRMS (Julian, 2011). Cognitive deficits manifest as decreased information processing speed and efficiency, reduced complex attention, poorer executive functioning, verbal fluency, and long term memory (Chiaravalloti and DeLuca, 2008).

\subsubsection{The neural basis of cognitive impairments in MS. White matter}

Traditionally MS has been associated with WM damage. MRI is routinely used as a diagnostic tool (Sumowski et al., 2018) and cognitive impairments are usually linked to accumulation of WM lesions seen as T2-weighted MRI hyperintensities on MRI scans (Calabrese et al., 2009; Yildiz et al., 2014). Widespread WM deterioration is present across whole brain. More specifically, structural WM atrophy can be found diffusely spanning frontal lobe regions, such as superior part of corona radiata, forceps minor, bilateral superior 
longitudinal fasciculus, through to temporo-occipital lobes - cingulum, bilateral fornix, bilateral ILF, bilateral IFOF, cortico-spinal tract, forceps major, bilateral cerebellar hemispheres, dorsal part of the pons, rostral part of the medulla oblongata, bilaterally. CC, corona radiata and thalamic radiations are also disrupted by the disease (Riccitelli et al., 2012; see Roman and Arnett, 2016, for review). This list of regions helps to illustrate the widespread nature of WM atrophy - and total WM lesion volume and area, as well as measures of global WM structural connectivity are linked to impaired executive functioning performance and global cognitive impairment (Nourbakhsh et al., 2016; Rao et al., 1989). This relationship between WM integrity and cognitive impairment can be observed in very early stages of MS diagnosis and, over time, cumulative increases in WM lesion volume parallel the progression of cognitive decline (Ouellette et al., 2018).

However, there is some further granularity in terms of WM damage and direct links to cognitive and executive deficits. It seems that mostly CC and frontal WM are implicated in executive deficits in MS. Similarly to HD and PD, disruption to the CC has been associated with impaired cognitive processing in MS, particularly reduced processing speed (Roosendaal et al., 2009). These patterns have also been observed in the benign phenotype of MS, where symptom expression is minimal, although not absent, for considerable periods post onset. Benign MS patients also display decreased FA values in the CC genu, associated with impaired verbal learning and memory, and decreased FA in the CC body, associated with poorer executive functioning more generally (Bester et al., 2013).

WM damage has been observed in frontal executive control and working memory networks, particularly in WM tracts connecting bilateral ACC, bilateral thalami, middle and IFG (Audoin et al., 2007). Decreased FA and increased Apparent Diffusion Coefficient (indicating neurodegeneration) in the frontolateral WM regions have been associated with reduced information processing speed and executive functioning (Roca et al., 2008). Decreased 
integrity in frontoparietal networks has been linked to lower attention (Llufriu et al., 2017). Reduced frontal WM volume has been linked to impaired inhibition (Ternes et al., 2019). Although not a WM structure per se, thalamic WM atrophy has been linked to poorer executive control, as measured by a battery of cognitive tests (Benedict et al., 2013). This is not surprising as thalamus is robustly implicated in MS in general.

Although WM connectivity is reduced at the whole brain level in MS, regional increases in WM connectivity correlating with impaired attention have also been observed (Llufriu et al., 2017). This pattern is mirrored in measures of functional connectivity where regional increases in functional connectivity can be observed despite global reductions in activity (Rocca et al., 2018). Overall reduction in resting state functional connectivity correlates with T2 lesion load and severity of cognitive impairment, and as such these patterns may indicate some sort of compensatory mechanisms.

\subsubsection{Subcortical grey matter}

Despite the clinical focus on WM impairment in MS, deterioration in both cortical and subcortical GM can be observed, although the exact pathogenesis and cause of demyelination and neuroaxonal degeneration of GM is not fully understood in this disease (Geurts and Barkhof, 2008). Even in the earliest stages of MS diagnosis, RRMS patients exhibit reduced volumes of the bilateral thalamus, hippocampus, caudate nuclei and putamen. Volumetric reductions in these structures have been linked to reduced processing speed, attention, working memory, executive functioning and wider cognitive impairments although neural impairment does not manifest behaviourally in the early stages of MS (Audoin et al., 2010). The thalamus and putamen are further associated with impairment on verbal fluency and category switching measures of executive control and reduction in thalamic and hippocampal volume is linked to visuospatial and visuoperceptual impairment (Debernard et al., 2015). Hippocampal volume 
has also been related to episodic memory and information processing speed (Koenig et al., 2014).

Structure most robustly showing links to cognitive impairment in MS, however, is the thalamus. This GM structure has been consistently implicated in MS and remains the most sensitive biomarker of the severity of neuropsychological decline (Papathanasiou et al., 2015; Schoonheim et al., 2015) with volume decreasing linearly as the disease progresses (Ouellette et al., 2018). Thalamic deterioration has also been showed to impact performance across a variety of cognitive domains. Benedict et al. (2013) showed that thalamic volume predicted performance in tasks measuring verbal learning and memory, cognitive processing speed in visual and auditory modalities, and higher executive function. These findings have been supported by results from a large multicentre study showing decreased thalamic volume and also increased functional activation to predict poorer information processing speed and executive functioning (Koini et al., 2016). Due to the central role of the thalamus in MS neuropathology, the authors called for clinical interventions targeting the thalamus in particular. Recall that the thalamus has been implicated in executive control and language control in bilingual individuals (Abutalebi and Green, 2016) and bilingualism has been shown to have an effect of thalamic shape and contribute to volumetric expansion of the structure in healthy adults (Burgaleta et al., 2016; Pliatsikas et al., 2017).

\subsubsection{Cortical grey matter}

MS can result in widespread deterioration in cortical GM across the frontal, parietal, temporal, and occipital lobes of the cortex, the bilateral insula and posterior cingulate cortex and bilateral cerebellum (Riccitelli et al., 2012). The scattered nature of cortical GM deficit is evident and a general association between global cortical GM volume and cognitive performance has been established (Calabrese et al., 2009; Fenu et al., 2018). There are also 
reports showing correlations between cortical GM thinning and both WM lesion volume and severity of cognitive impairment. This is most evident in the cingulate gyrus, insula and, and frontal regions of the brain (Charil et al., 2007). In a large multicentre study, it was found that while there was a global cortical GM atrophy in MS, there were only marginal differences in cortical GM thinning between cognitively impaired and cognitively preserved MS patients. Links between GM thinning in the parietal regions and visual memory performance, as well as thinning in the insula and verbal memory were also established (Tillema et al., 2016).

While cortical GM decline is rather widespread and general, one structure that seems to contribute to cognitive performance in MS is the cerebellum. Studies have found atrophy in the right cerebellum to correlate with scores of the Extended Disability Status Scale (EDSS) (although there is a rather significant motor component to EDSS) (Audoin et al., 2010) and there is evidence, supplementing previous knowledge of cerebellar involvement in motor dysfunction in MS, showing correlation between the cerebellar volume and cognitive performance in MS (Weier et al., 2014). Looking at the cerebellum in finer detail, deterioration of some parts of it would underlie motor disability, while others would predict to cognitive deficits (Grothe et al., 2017).

In sum, global GM damage predicts the severity of cognitive impairment. However, on a regional level, cortical GM atrophy does not seem to play a role in MS-related cognitive and executive deficits comparable to the effects arising from precise and localised WM and subcortical GM deterioration.

\subsubsection{Evidence for general cognitive/neural reserve in $M S$}

There is extensive evidence that cognitively active lifestyles have an impact on cognitive and neural outcomes in MS. Factors such as premorbid intelligence measures (Sumowski et al., 2009), engagement in reading and writing (Sumowski et al., 2016), education 
level, premorbid leisure activities and IQ (Amato et al., 2013; Fenu et al., 2018) are associated with higher functioning, Longitudinally, MS patients with more years of education and higher North American Adult Reading Test (NAART) scores (measure of verbal intelligence) showed less cognitive decline over time a five year period (Benedict et al., 2010). These data suggest that cognitively demanding activities improves brain health and ensures longer protection from cognitive impairment in MS (Giovannoni et al., 2016) and, indeed, cognitive intervention in MS patients leads to improved neuropsychological outcomes (Flavia et al., 2010).

\subsubsection{MS and bilingualism}

Unlike the rather extensive body of literature testing the contribution of cognitive and neural reserves to the progression of MS, so far only very limited research has directly examined the cognitive and neural effects of bilingualism on MS patients. However, two recent, small-scale studies have found positive indicators for the impact of bilingualism on executive control tasks in MS. First, using a modified flanker task (following Costa et al., 2009), as a measure of inhibition and monitoring, Aveledo et al., (2019) showed that while there were no effects of bilingualism on inhibition in MS, bilingual MS patients showed similar monitoring performance to healthy bilingual controls. This was in contrast to monolingual participants where MS patients showed significantly larger monitoring cost than healthy monolingual controls, thus suggesting at least partial bilingualism-related cognitive reserve in MS. Second, bilingual participants with RRMS were found to display better non-verbal executive functioning in comparison to monolingual participants matched for age, sex, and socio-economic status (Soltani et al., 2018). While these studies indicate some degree of neuroprotection from the bilingual experience it should be noted that no differences between the bilingual and monolingual cohorts were found on Flanker reaction times or verbal executive function measures in the same studies. Nevertheless, given the low participants numbers and 
consequently low statistical power, the results from these initial studies are promising and warrant further exploration of the impact of bilingualism on the cognitive profile in MS.

To summarise, MS is a neurodegenerative disorder affecting both WM and GM across the whole central nervous system. Although the disorder is somewhat more different to AD than $\mathrm{HD}$ and/or PD, all of these diseases are related by the virtue of progressive neurodegeneration. Structures associated with cognitive and executive dysfunction in MS are frontal WM networks, CC, and the thalamus, among others. These structures are also implicated in bilingualism and in other disorders discussed above. As such, bilingualism may have an impact of building up of neural reserve in these regions, which may have an impact on contributing to cognitive reserve in MS.

\section{Discussion and Conclusions: Recommended directions to test bilingualism and general neurodegeneration more directly in the near future}

Having gone through the cognitive and neuroanatomical literatures for both healthy (younger and older) bilinguals, as well as those pertaining to neurodegenerative clinical populations, a few points stand out related to the goals of this review. In light of gains in cognitive and neural reserves that active bilingualism is likely to provide, the evidence across the lifespan that supports such a claim and especially the promising indications from work on $\mathrm{AD}$ and $\mathrm{MCI}$, there is a strong case to be made that more linking research is warranted. Nevertheless, investigating bilingualism as an ameliorative factor has not yet been capitalized on. Indeed, the notion of cognitive and neural reserve is pervasive throughout the studies of neuropathology of degenerative disorders in general, yet few are the studies that investigate bilingualism within this general remit, despite very compelling reasons to the contrary. To the extent that bilingualism is one ubiquitous activity that catalyses accruing in cognitive and brain reserves over time, it makes sense that research on bilingualism and neurodegenerative 
disorders should be more prolific than it presently is and, more importantly, that there would be a centralized goal of such research. At present, as reviewed above, there is too little research than the importance of the potential gains warrant. For the existent, yet scant research—good as much of it is - there is a lack of a central theme or goal: studies on distinct disorders do not cluster, as we submit they should, with common questions, aims and comparability of methods/procedures. This review, beyond bringing what exists together in one place, is also meant to be a call-to-action from quantitative as well as qualitative shifts in this regard: not only are more studies needed, but the links between them need to be better understood. Instead of studying bilingualism and $\mathrm{AD}$ or bilingualism and $\mathrm{HD}$, for example, we would be wise to see each as part of a general program to study the potential effects of bilingualism on neurocognitive disorders in general. This does not mean, of course, that specific questions and goals should not be asked/had for individual disorders. Conversely, we submit that larger questions transcending differences from disease-specific pathology interactions should be articulated at a higher level where individual disorders provide evidence at a higher level.

The common aim is to ask and create methods to answer the following main question: through the lens of bilingualism as a source of accruing cognitive and neural reserves, what is the linked role of bilingualism in the potential attenuation of symptom onset/progression for neurodegenerative disease? The exact mechanisms of how bilingualism adds to reserves and what the conditions of bilingualism are for such (i.e., the traits and behaviours of (in)active bilingualism that explain individual differences and result in optimal effects) are a matter of continuous research. Enough promising research, as we have reviewed above, exists to underscore the need for all of these questions to be investigated in parallel. Of course, as we understand the mechanisms involved and the weightings of cognitive, linguistic and environmental factors that give rise to bilingualism-induced effects to the mind/brain better, this will decisively affect our work on examining the role bilingualism plays in 
neurodegenerative disorders. Waiting, however, for all debates to be settled and questions to be answered in this parallel program is, however, not wise. The costs and potential benefits of such knowledge are too high. Moreover, at worst, answers in the more established parallel research will only fine-tune (progressively) how the bilingualism and neurodegenerative literature asks its questions and implements its designs, for example, selection for sub-groups of participants, adding factors as regressors for individual differences in our models and the like. It should not fundamentally change the goals and overarching questions.

Since previous research seems to point in the direction that bilingualism as a lifelong activity is a very good candidate as a contributor to cognitive and neural reserves, exhaustively investigating the common question posed above is imperative and beneficial in multifarious ways. To the extent that there is some ameliorative (neutral or subtractive) effect of bilingualism across diseases (with comparable populations of bilinguals of course) then such could highlight underlying commonalities across pathologies — where each relates to common brain structures that are better preserved or where each is otherwise subject to compensation from reserves. Differences in the same regard would provide a distinct mirror into the limits cognitive and/or neural reserve have for subparts of particular diseases.

As it pertains to intervention, we can appreciate perhaps the most important reasons to forge a new program. If bilingualism plays some role, then knowing precisely what this would be is all the more imperative since bilingualism is an organic process that can be supported better, promoted, avoided and/or even created where it does not currently exist. As scientists, it is not within our remit to associate evaluative labels to phenomena we observe. As such, we have tried to avoid throughout words like advantage, which is often used in bilingualism and cognition circles. While we cannot label something as being an advantage per se, it is possible to claim that something is more advantageous to a certain desired result than something else. Such is the very remit of intervention, making the most beneficial recommendations towards a 
desired goal. If bilingualism creates opportunities for increases in reserves and to the extent such reserves ameliorate the devastating impact of neurocognitive diseases, if only in masking symptoms, then at present we might refer to bilingualism as an advantageous intervention. This is mainly because at present there are very few treatments for neurodegenerative disorders beyond those designed to prolong the onset of severe symptoms and palliative care. But science is advancing quickly. In the foreseeable future, many of these diseases are predicted to be much better understood or even have been cured (e.g., Lindvall and Kokaia, 2006; Wray and Fox, 2016). But early diagnosis is crucial precisely because the undoing of physiological damage to the brain is irreversible once set in. And so, while bilingualism can be viewed as an advantageous intervention today, it could be quite the opposite in decades to come. Having an onset of overt symptoms 4-5 years later while the brain's deterioration is compensated for via cognitive and neural reserve would become severely disadvantageous when better treatments become available. Nevertheless, and perhaps even more important in such a scenario, is knowing definitively if there is the loop with bilingualism we have suggested herein.

In sum, the initial findings about bilingualism as a factor delaying the onset of clinical symptoms of AD came from studies looking at medical records (e.g., Alladi et al., 2013). Since then, the field has moved on to experimental studies testing these claims and directly examining the differences between monolingual and bi- or multilingual AD and MCI patients (e.g., Duncan et al., 2018). As we have suggested, though, the field is ready to expand this more broadly to beyond these two disorders. As a first step, it would be extremely valuable to see similar studies to Alladi et al. (2013), at least looking at medical records done for the effects of bilingualism on HD, PD, MS and more. This should be attainable with relative ease, if the right demographic data are collected. At the same time, as a field, we need to begin (or continue, as is the case for MCI and AD) experimental research, examining clinical effects of bilingualism directly in patient populations - as evident from the review above, there are a 
mere few studies per disorder that cannot provide satisfactory amount of evidence for global conclusions. There is also a subset of literature looking at acute, non-progressive neurodegeneration and the effects of bilingualism on it, not reviewed here due to the fundamentally different clinical profile of such disorders. However, akin to the studies reviewed herein, they predict better clinical outcomes, due to hypothesized bolstered neural and/or cognitive reserves. Most prominently, it is reported that bilingualism is a predictive factor for improved post-stroke cognitive outcomes (Alladi et al., 2016), as well as less severe expression of post-stroke aphasia symptoms (Paplikar et al., 2018). These preliminary results suggest neurocognitive effects of bilingualism even in scenarios of non-progressive neurodegeneration and opens up research avenues encompassing an increasingly wider scope on interactions between bilingualism and neurological conditions.

The program that emerges will have to consider the individually complex and variable nature of the bilingual experience itself. To this end, it is recommended that studies adopt a single common or maximally comparable background questionnaires such as the Language and Social Background Questionnaire (LSBQ) (Anderson et al., 2018c) or the Language Experience and Proficiency Questionnaire (LEAP-Q) (Marian et al., 2007). These are available in an impressive number of languages and do an excellent job in gathering relevant information and provide normed rubrics for composite scoring at various levels. Biological and clinical outcomes may vary depending on a range of factors, such as, but not limited to age of acquisition, frequency of language use, immersion in language environments and more. Moreover, in our effort to make sure that this emerging program contributes to better understanding of the exact underlying biological mechanisms of bilingualism and its contribution to improved clinical outcomes, this will require joining forces between biologists, cognitive scientists, psycholinguists, neuroscientists and many more. 


\section{Funding}

This research was supported by the University of Reading Anniversary PhD Scholarship (awarded to TV).

\section{Declaration of interest}

The authors declare no conflict of interest. 


\section{Bibliography}

Aarsland, D., Creese, B., Politis, M., Chaudhuri, K.R., Ffytche, D.H., Weintraub, D., Ballard, C., 2017. Cognitive decline in Parkinson disease. Nat. Rev. Neurol. 13, 217-231. https://doi.org/10.1038/nrneurol.2017.27

Abutalebi, J., 2008. Neural aspects of second language representation and language control. Acta Psychol. (Amst). 128, 466-478. https://doi.org/10.1016/j.actpsy.2008.03.014

Abutalebi, J., Canini, M., Della Rosa, P.A., Sheung, L.P., Green, D.W., Weekes, B.S., 2014. Bilingualism protects anterior temporal lobe integrity in aging. Neurobiol. Aging 35, 2126-2133. https://doi.org/10.1016/j.neurobiolaging.2014.03.010

Abutalebi, J., Della Rosa, P.A., Green, D.W., Hernandez, M., Scifo, P., Keim, R., Cappa, S.F., Costa, A., 2012. Bilingualism tunes the anterior cingulate cortex for conflict monitoring. Cereb. Cortex 22, 2076-2086. https://doi.org/10.1093/cercor/bhr287

Abutalebi, J., Green, D., 2007. Bilingual language production: The neurocognition of language representation and control, Journal of Neurolinguistics. https://doi.org/10.1016/j.jneuroling.2006.10.003

Abutalebi, J., Green, D.W., 2016. Neuroimaging of language control in bilinguals: Neural adaptation and reserve. Bilingualism 19, 689-698.

https://doi.org/10.1017/S1366728916000225

Abutalebi, J., Guidi, L., Borsa, V., Canini, M., Della Rosa, P.A., Parris, B.A., Weekes, B.S., 2015. Bilingualism provides a neural reserve for aging populations. Neuropsychologia 69, 201-210. https://doi.org/10.1016/j.neuropsychologia.2015.01.040

Alladi, S., Bak, T.H., Duggirala, V., Surampudi, B., Shailaja, M., Shukla, A.K., Chaudhuri, J.R., Kaul, S., 2013. Bilingualism delays age at onset of dementia, indipendent of education and immigration status. Neurology 81, 1938-1944. https://doi.org/10.1212/01.WNL.0000437347.92583.fc 
Alladi, S., Bak, T.H., Mekala, S., Rajan, A., Chaudhuri, J.R., Mioshi, E., Krovvidi, R., Surampudi, B., Duggirala, V., Kaul, S., 2016. Impact of bilingualism on cognitive outcome after stroke. Stroke 47, 258-261.

https://doi.org/10.1161/STROKEAHA.115.010418

Amato, M.P., Razzolini, L., Goretti, B., Stromillo, M.L., Rossi, F., Giorgio, A., Hakiki, B., Giannini, M., Pastò, L., Portaccio, E., De Stefano, N., 2013. Cognitive reserve and cortical atrophy in multiple sclerosis: A longitudinal study. Neurology 80, 1728-1733. https://doi.org/10.1212/WNL.0b013e3182918c6f

Amato, M.P., Zipoli, V., Portaccio, E., 2006. Multiple sclerosis-related cognitive changes: A review of cross-sectional and longitudinal studies. J. Neurol. Sci. 245, 41-46. https://doi.org/10.1016/j.jns.2005.08.019

Anderson, John A.E., Chung-Fat-Yim, A., Bellana, B., Luk, G., Bialystok, E., $2018 \mathrm{a}$. Language and cognitive control networks in bilinguals and monolinguals. Neuropsychologia 117, 352-363. https://doi.org/10.1016/j.neuropsychologia.2018.06.023

Anderson, John A.E., Grundy, J.G., De Frutos, J., Barker, R.M., Grady, C., Bialystok, E., 2018b. Effects of bilingualism on white matter integrity in older adults. Neuroimage 167, 143-150. https://doi.org/10.1016/j.neuroimage.2017.11.038

Anderson, John A.E., Mak, L., Keyvani Chahi, A., Bialystok, E., 2018c. The language and social background questionnaire: Assessing degree of bilingualism in a diverse population. Behav. Res. Methods 50, 250-263. https://doi.org/10.3758/s13428-0170867-9

Andrews, S.C., Domínguez, J.F., Mercieca, E.C., Georgiou-Karistianis, N., Stout, J.C., 2015. Cognitive interventions to enhance neural compensation in Huntington's disease. Neurodegener. Dis. Manag. 5, 155-164. https://doi.org/10.2217/nmt.14.58 
Antoniou, M., 2019. The Advantages of Bilingualism Debate. Annu. Rev. Linguist. 5, 1-21. https://doi.org/10.1146/annurev-linguistics-011718-011820

Ardila, A., Fatima, S., Rosselli, M., 2019. Dysexecutive Syndromes, International Encyclopedia of the Social \& Behavioral Sciences. Springer International Publishing, Cham. https://doi.org/10.1007/978-3-030-25077-5

Armstrong, M.J., Naglie, G., Duff-Canning, S., Meaney, C., Gill, D., Eslinger, P.J., Zadikoff, C., Mapstone, M., Chou, K.L., Persad, C., Litvan, I., Mast, B.T., Fox, S., Tang-Wai, D.F., Marras, C., 2012. Roles of Education and IQ in Cognitive Reserve in Parkinsons Disease-Mild Cognitive Impairment. Dement. Geriatr. Cogn. Dis. Extra 2, 343-352. https://doi.org/10.1159/000341782

Audoin, B., Guye, M., Reuter, F., Au Duong, M. Van, Confort-Gouny, S., Malikova, I., Soulier, E., Viout, P., Chérif, A.A., Cozzone, P.J., Pelletier, J., Ranjeva, J.P., 2007. Structure of WM bundles constituting the working memory system in early multiple sclerosis: A quantitative DTI tractography study. Neuroimage 36, 1324-1330. https://doi.org/10.1016/j.neuroimage.2007.04.038

Audoin, B., Zaaraoui, W., Reuter, F., Rico, A., Malikova, I., Confort-Gouny, S., Cozzone, P.J., Pelletier, J., Ranjeva, J.P., 2010. Atrophy mainly affects the limbic system and the deep grey matter at the first stage of multiple sclerosis. J. Neurol. Neurosurg. Psychiatry 81, 690-695. https://doi.org/10.1136/jnnp.2009.188748

Auning, E., Kjærvik, V.K., Selnes, P., Aarsland, D., Haram, A., Bjørnerud, A., Hessen, E., Esnaashari, A., Fladby, T., 2014. White matter integrity and cognition in Parkinson's disease: A cross-sectional study. BMJ Open 4, 1-10. https://doi.org/10.1136/bmjopen2013-003976

Aveledo, F., Higueras, Y., Marinis, T., Bose, A., Pliatsikas, C., Meldaña, A., MartínezGuinés, M.L., 2019. Multiple sclerosis and bilingualism : some initial findings. Linguist. 
Approaches to Biling. ISSN 1879-9272 (In Press)

Aylward, E.H., Nopoulos, P.C., Ross, C.A., Langbehn, D.R., Pierson, R.K., Mills, J.A., Johnson, H.J., Magnotta, V.A., Juhl, A.R., Paulsen, J.S., 2011. Longitudinal change in regional brain volumes in prodromal Huntington disease. J. Neurol. Neurosurg. Psychiatry 82, 405-410. https://doi.org/10.1136/jnnp.2010.208264

Backman, L., Robins-Wahlin, T., Lundin, A., Ginovart, N., Farde, L., 1997. Cognitive deficits in Huntington's disease are predicted by dopaminergic PET markers and brain volumes. Brain 120, 2207-2217. https://doi.org/10.1093/brain/120.12.2207

Bak, T.H., Robertson, I., 2017. Biology enters the scene-a new perspective on bilingualism, cognition, and dementia. Neurobiol. Aging 50, iii-iv. https://doi.org/10.1016/j.neurobiolaging.2016.10.020

Baum, S., Titone, D., 2014. Moving toward a neuroplasticity view of bilingualism, executive control, and aging. Appl. Psycholinguist. 35, 857-894. https://doi.org/10.1017/S0142716414000174

Bellebaum, C., Daum, I., 2007. Cerebellar involvement in executive control. Cerebellum 6, 184-192. https://doi.org/10.1080/14734220601169707

Benedict, R.H.B., Hulst, H.E., Bergsland, N., Schoonheim, M.M., Dwyer, M.G., WeinstockGuttman, B., Geurts, J.J.G., Zivadinov, R., 2013. Clinical significance of atrophy and white matter mean diffusivity within the thalamus of multiple sclerosis patients. Mult. Scler. J. 19, 1478-1484. https://doi.org/10.1177/1352458513478675

Benedict, R.H.B., Morrow, S.A., Weinstock Guttman, B., Cookfair, D., Schretlen, D.J., 2010. Cognitive reserve moderates decline in information processing speed in multiple sclerosis patients. J. Int. Neuropsychol. Soc. 16, 829-835. https://doi.org/10.1017/S1355617710000688

Beste, C., Saft, C., Andrich, J., Gold, R., Falkenstein, M., 2008. Response inhibition in 
Huntington's disease-A study using ERPs and sLORETA. Neuropsychologia 46, 12901297. https://doi.org/10.1016/j.neuropsychologia.2007.12.008

Bester, M., Lazar, M., Petracca, M., Babb, J.S., Herbert, J., Grossman, R.I., Inglese, M., 2013. Tract-specific white matter correlates of fatigue and cognitive impairment in benign multiple sclerosis. J. Neurol. Sci. 330, 61-66.

https://doi.org/10.1016/j.jns.2013.04.005

Bialystok, E., 2017. The bilingual adaptation: How minds accommodate experience. Psychol. Bull. 143, 233-262. https://doi.org/10.1037/bul0000099

Bialystok, E., Craik, F.I.M., Binns, M.A., Ossher, L., Freedman, M., 2014a. Effects of bilingualism on the age of onset and progression of MCI and AD: Evidence from executive function tests. Neuropsychology 28, 290-304. https://doi.org/10.1037/neu0000023

Bialystok, E., Craik, F.I.M., Klein, R., Viswanathan, M., 2004. Bilingualism, Aging, and Cognitive Control: Evidence From the Simon Task. Psychol. Aging 19, 290-303. https://doi.org/10.1037/0882-7974.19.2.290

Bialystok, E., Craik, F.I.M., Luk, G., 2012. Bilingualism: Consequences for mind and brain. Trends Cogn. Sci. 16, 240-249. https://doi.org/10.1016/j.tics.2012.03.001

Bialystok, E., Craik, F.I.M.M., Freedman, M., 2007. Bilingualism as a protection against the onset of symptoms of dementia. Neuropsychologia 45, 459-464. https://doi.org/10.1016/j.neuropsychologia.2006.10.009

Bialystok, E., Poarch, G., Luo, L., Craik, F.I.M.M., 2014b. Effects of Bilingualism and Aging on Executive Function and Working Memory. Psychol Aging 29, 696-705. https://doi.org/10.1016/j.immuni.2010.12.017.Two-stage

Bledsoe, I.O., Stebbins, G.T., Merkitch, D., Goldman, J.G., 2018. White matter abnormalities in the corpus callosum with cognitive impairment in Parkinson disease. Neurology 91, 
e2244-e2255. https://doi.org/10.1212/WNL.0000000000006646

Blennow, K., Vanmechelen, E., Hampel, H., 2001. CSF total tau, A $\beta 42$ and phosphorylated tau protein as biomarkers for Alzheimer's disease. Mol. Neurobiol. 24, 87-97. https://doi.org/10.1385/MN:24:1-3:087

Bohanna, I., Georgiou-Karistianis, N., Sritharan, A., Asadi, H., Johnston, L., Churchyard, A., Egan, G., 2011. Diffusion Tensor Imaging in Huntington's disease reveals distinct patterns of white matter degeneration associated with motor and cognitive deficits. Brain Imaging Behav. 5, 171-180. https://doi.org/10.1007/s11682-011-9121-8

Bonner-Jackson, A., Long, J.D., Westervelt, H., Tremont, G., Aylward, E., Paulsen, J.S., 2013. Cognitive reserve and brain reserve in prodromal Huntington's disease. J. Int. Neuropsychol. Soc. 19, 739-750. https://doi.org/10.1017/S1355617713000507

Bourbon-Teles, J., Bells, S., Jones, D.K., Coulthard, E., Rosser, A., Metzler-Baddeley, C., 2019. Myelin breakdown in human Huntington's disease: Multi-modal evidence from diffusion MRI and quantitative magnetization transfer. Neuroscience 403, 79-92. https://doi.org/10.1016/j.neuroscience.2017.05.042

Brück, A., Kurki, T., Kaasinen, V., Vahlberg, T., Rinne, J.O., 2004. Hippocampal and prefrontal atrophy in patients with early non-demented Parkinson's disease is related to cognitive impairment. J. Neurol. Neurosurg. Psychiatry 75, 1467-1469. https://doi.org/10.1136/jnnp.2003.031237

Burgaleta, M., Sanjuán, A., Ventura-Campos, N., Sebastian-Galles, N., Ávila, C., 2016. Bilingualism at the core of the brain. Structural differences between bilinguals and monolinguals revealed by subcortical shape analysis. Neuroimage 125, 437-445. https://doi.org/10.1016/j.neuroimage.2015.09.073

Calabrese, M., Agosta, F., Rinaldi, F., Mattisi, I., Grossi, P., Favaretto, A., Atzori, M., Bernardi, V., Barachino, L., Rinaldi, L., Perini, P., Gallo, P., Filippi, M., 2009. Cortical 
Lesions and Atrophy Associated With Cognitive Impairment in Relapsing-Remitting Multiple Sclerosis. Arch. Neurol. 66, 1144-1150.

https://doi.org/10.1001/archneurol.2009.174

Calabria, M., Costa, A., Green, D.W., Abutalebi, J., 2018a. Neural basis of bilingual language control. Ann. N. Y. Acad. Sci. 1426, 221-235.

https://doi.org/10.1111/nyas.13879

Calabria, M., Hernández, M., Branzi, F.M., Costa, A., 2012. Qualitative differences between bilingual language control and executive control: Evidence from task-switching. Front. Psychol. 3, 1-10. https://doi.org/10.3389/fpsyg.2011.00399

Calabria, M., Pérez Pérez, J., Martínez-Horta, S., Horta-Barba, A., Carceller, M., Kulisevsky, J., Costa, A., 2018b. Language reconfiguration in bilinguals. Linguist. Approaches to Biling. https://doi.org/10.1075/lab.18022.cal

Calvo, N., García, A.M., Manoiloff, L., Ibáñez, A., 2016. Bilingualism and cognitive reserve: A critical overview and a plea for methodological innovations. Front. Aging Neurosci. https://doi.org/10.3389/fnagi.2015.00249

Chang, Y., 2014. Reorganization and plastic changes of the human brain associated with skill learning and expertise. Front. Hum. Neurosci. 8, 1-7.

https://doi.org/10.3389/fnhum.2014.00035

Chao, T.K., Hu, J., Pringsheim, T., 2017. Risk factors for the onset and progression of Huntington disease. Neurotoxicology 61, 79-99. https://doi.org/10.1016/j.neuro.2017.01.005

Charil, A., Dagher, A., Lerch, J.P., Zijdenbos, A.P., Worsley, K.J., Evans, A.C., 2007. Focal cortical atrophy in multiple sclerosis: Relation to lesion load and disability. Neuroimage 34, 509-517. https://doi.org/10.1016/j.neuroimage.2006.10.006

Chaudhuri, K.R., Healy, D.G., Schapira, A.H., 2006. Non-motor symptoms of Parkinson's 
disease: diagnosis and management. Lancet Neurol. 5, 235-245.

https://doi.org/10.1016/S1474-4422(06)70373-8

Chen, F.X., Kang, D.Z., Chen, F.Y., Liu, Y., Wu, G., Li, X., Yu, L.H., Lin, Y.X., Lin, Z.Y., 2016. Gray matter atrophy associated with mild cognitive impairment in Parkinson's disease. Neurosci. Lett. 617, 160-165. https://doi.org/10.1016/j.neulet.2015.12.055

Chiaravalloti, N.D., DeLuca, J., 2008. Cognitive impairment in multiple sclerosis. Lancet Neurol. 7, 1139-1151. https://doi.org/10.1016/S1474-4422(08)70259-X

Ciarmiello, A., Cannella, M., Lastoria, S., Simonelli, M., Frati, L., Rubinsztein, D.C., Squitieri, F., 2006. Brain white-matter volume loss and glucose hypometabolism precede the clinical symptoms of Huntington's disease. J. Nucl. Med. 47, 215-22.

Coppen, E.M., Jacobs, M., van den Berg-Huysmans, A.A., van der Grond, J., Roos, R.A.C., 2018. Grey matter volume loss is associated with specific clinical motor signs in Huntington's disease. Park. Relat. Disord. 46, 56-61. https://doi.org/10.1016/j.parkreldis.2017.11.001

Costa, A., Hernández, M., Costa-Faidella, J., Sebastián-Gallés, N., 2009. On the bilingual advantage in conflict processing: Now you see it, now you don't. Cognition 113, 135149. https://doi.org/10.1016/j.cognition.2009.08.001

Costa, A., Hernández, M., Sebastián-Gallés, N., 2008. Bilingualism aids conflict resolution: Evidence from the ANT task. Cognition 106, 59-86. https://doi.org/10.1016/j.cognition.2006.12.013

Craik, F.I.M., Bialystok, E., Freedman, M., 2010. Delaying the onset of Alzheimer disease. Neurology 75, 1726-1729. https://doi.org/10.1212/WNL.0b013e3181fc2a1c

Craufurd, D., Thompson, J.C., Snowden, J.S., 2001. Behavioral changes in Huntington Disease. Neuropsychiatry. Neuropsychol. Behav. Neurol. 14, 219-26.

Cree, B.A.C., Gourraud, P.A., Oksenberg, J.R., Bevan, C., Crabtree-Hartman, E., Gelfand, 
J.M., Goodin, D.S., Graves, J., Green, A.J., Mowry, E., Okuda, D.T., Pelletier, D., von

Büdingen, H.C., Zamvil, S.S., Agrawal, A., Caillier, S., Ciocca, C., Gomez, R., Kanner, R., Lincoln, R., Lizee, A., Qualley, P., Santaniello, A., Suleiman, L., Bucci, M., Panara, V., Papinutto, N., Stern, W.A., Zhu, A.H., Cutter, G.R., Baranzini, S., Henry, R.G., Hauser, S.L., 2016. Long-term evolution of multiple sclerosis disability in the treatment era. Ann. Neurol. 80, 499-510. https://doi.org/10.1002/ana.24747

Cruickshank, T.M., Thompson, J.A., Domínguez D, J.F., Reyes, A.P., Bynevelt, M., Georgiou-Karistianis, N., Barker, R.A., Ziman, M.R., 2015. The effect of multidisciplinary rehabilitation on brain structure and cognition in Huntington's disease: An exploratory study. Brain Behav. 5, 1-10. https://doi.org/10.1002/brb3.312

Curtis, A.F., Masellis, M., Camicioli, R., Davidson, H., Tierney, M.C., 2019. Cognitive profile of non-demented Parkinson's disease: Meta-analysis of domain and sex-specific deficits. Park. Relat. Disord. 60, 32-42. https://doi.org/10.1016/j.parkreldis.2018.10.014

Dash, T., Berroir, P., Joanette, Y., Ansaldo, A.I., 2019. Alerting, orienting, and executive control: The effect of bilingualism and age on the subcomponents of attention. Front. Neurol. 10, 1-12. https://doi.org/10.3389/fneur.2019.01122

Davies, S.W., Turmaine, M., Cozens, B.A., DiFiglia, M., Sharp, A.H., Ross, C.A., Scherzinger, E., Wanker, E.E., Mangiarini, L., Bates, G.P., 1997. Formation of Neuronal Intranuclear Inclusions Underlies the Neurological Dysfunction in Mice Transgenic for the HD Mutation. Cell 90, 537-548. https://doi.org/10.1016/S0092-8674(00)80513-9 de Bruin, A., Bak, T.H., Della Sala, S., 2015. Examining the effects of active versus inactive bilingualism on executive control in a carefully matched non-immigrant sample. J. Mem. Lang. 85, 15-26. https://doi.org/10.1016/j.jml.2015.07.001

De Cat, C., Gusnanto, A., Serratrice, L., 2018. Identifying a threshold for the executive function advantage in bilingual children. Stud. Second Lang. Acquis. 40, 119-151. 
https://doi.org/10.1017/S0272263116000486

De Stefano, N., Airas, L., Grigoriadis, N., Mattle, H.P., O’Riordan, J., Oreja-Guevara, C., Sellebjerg, F., Stankoff, B., Walczak, A., Wiendl, H., Kieseier, B.C., 2014. Clinical relevance of brain volume measures in multiple sclerosis. CNS Drugs 28, 147-156. https://doi.org/10.1007/s40263-014-0140-z

Debernard, L., Melzer, T.R., Alla, S., Eagle, J., Van Stockum, S., Graham, C., Osborne, J.R., Dalrymple-Alford, J.C., Miller, D.H., Mason, D.F., 2015. Deep grey matter MRI abnormalities and cognitive function in relapsing-remitting multiple sclerosis. Psychiatry Res. - Neuroimaging 234, 352-361. https://doi.org/10.1016/j.pscychresns.2015.10.004

Della Nave, R., Ginestroni, A., Tessa, C., Giannelli, M., Piacentini, S., Filippi, M., Mascalchi, M., 2010. Regional distribution and clinical correlates of white matter structural damage in Huntington disease: A tract-based spatial statistics study. Am. J. Neuroradiol. 31, 1675-1681. https://doi.org/10.3174/ajnr.A2128

DeLuca, V., Rothman, J., Bialystok, E., Pliatsikas, C., 2020. Duration and extent of bilingual experience modulate neurocognitive outcomes. Neuroimage 204, 116222. https://doi.org/10.1016/j.neuroimage.2019.116222

DeLuca, V., Rothman, J., Bialystok, E., Pliatsikas, C., 2019. Redefining bilingualism as a spectrum of experiences that differentially affects brain structure and function. Proc. Natl. Acad. Sci. 116, 7565-7574. https://doi.org/10.1073/pnas.1811513116

Di Paola, M., Luders, E., Cherubini, A., Sanchez-Castaneda, C., Thompson, P.M., Toga, A.W., Caltagirone, C., Orobello, S., Elifani, F., Squitieri, F., Sabatini, U., 2012. Multimodal MRI analysis of the corpus callosum reveals white matter differences in presymptomatic and early Huntington's disease. Cereb. Cortex 22, 2858-2866. https://doi.org/10.1093/cercor/bhr360 
Douaud, G., Behrens, T.E., Poupon, C., Cointepas, Y., Jbabdi, S., Gaura, V., Golestani, N., Krystkowiak, P., Verny, C., Damier, P., Bachoud-Lévi, A.-C.C., Hantraye, P., Remy, P., 2009. In vivo evidence for the selective subcortical degeneration in Huntington's disease. Neuroimage 46, 958-966. https://doi.org/10.1016/j.neuroimage.2009.03.044

Duncan, G.W., Firbank, M.J., Yarnall, A.J., Khoo, T.K., Brooks, D.J., Barker, R.A., Burn, D.J., O’Brien, J.T., 2016. Gray and white matter imaging: A biomarker for cognitive impairment in early Parkinson's disease? Mov. Disord. 31, 103-110. https://doi.org/10.1002/mds.26312

Duncan, H.D., Nikelski, J., Pilon, R., Steffener, J., Chertkow, H., Phillips, N.A., 2018. Structural brain differences between monolingual and multilingual patients with mild cognitive impairment and Alzheimer disease: Evidence for cognitive reserve. Neuropsychologia 109, 270-282. https://doi.org/10.1016/j.neuropsychologia.2017.12.036

Eidelberg, D., Surmeier, D.J., 2011. Review series Brain networks in Huntington disease. J. Neurosci. 121, 484-492. https://doi.org/10.1172/JCI45646.484

Estanga, A., Ecay-Torres, M., Ibañez, A., Izagirre, A., Villanua, J., Garcia-Sebastian, M., Iglesias Gaspar, M.T., Otaegui-Arrazola, A., Iriondo, A., Clerigue, M., Martinez-Lage, P., 2017. Beneficial effect of bilingualism on Alzheimer's disease CSF biomarkers and cognition. Neurobiol. Aging 50, 144-151. https://doi.org/10.1016/j.neurobiolaging.2016.10.013

Feinstein, A., Deluca, J., Baune, B.T., Filippi, M., Lassman, H., 2013. Cognitive and neuropsychiatric disease manifestations in MS. Mult. Scler. Relat. Disord. 2, 4-12. https://doi.org/10.1016/j.msard.2012.08.001

Fenu, G., Lorefice, L., Arru, M., Sechi, V., Loi, L., Contu, F., Cabras, F., Coghe, G., Frau, J., Fronza, M., Sbrescia, G., Lai, V., Boi, M., Mallus, S., Murru, S., Porcu, A., Barracciu, 
M.A., Marrosu, M.G., Cocco, E., 2018. Cognition in multiple sclerosis: Between cognitive reserve and brain volume. J. Neurol. Sci. 386, 19-22.

https://doi.org/10.1016/j.jns.2018.01.011

Ferri, C.P., Prince, M., Brayne, C., Brodaty, H., Fratiglioni, L., Ganguli, M., Hall, K., Hasegawa, K., Hendrie, H., Huang, Y., Jorm, A., Mathers, C., Menezes, P.R., Rimmer, E., Scazufca, M., 2005. Global prevalence of dementia: a Delphi consensus study. Lancet 366, 2112-2117. https://doi.org/10.1016/S0140-6736(05)67889-0

Flavia, M., Stampatori, C., Zanotti, D., Parrinello, G., Capra, R., 2010. Efficacy and specificity of intensive cognitive rehabilitation of attention and executive functions in multiple sclerosis. J. Neurol. Sci. 288, 101-105. https://doi.org/10.1016/j.jns.2009.09.024

Garcia-Gorro, C., Garau-Rolandi, M., Escrichs, A., Rodriguez-Dechicha, N., Vaquer, I., Subira, S., Calopa, M., Martinez-Horta, S., Perez-Perez, J., Kulisevsky, J., Muñoz, E., Santacruz, P., Ruiz-Idiago, J., Mareca, C., de Diego-Balaguer, R., Camara, E., 2019. An active cognitive lifestyle as a potential neuroprotective factor in Huntington's disease. Neuropsychologia 122, 116-124. https://doi.org/10.1016/j.neuropsychologia.2018.10.017

Gawrys, L., Falkiewicz, M., Pilacinski, A., Riegel, M., Piatkowska-Janko, E., Bogorodzki, P., Wolak, T., Andrysiak, R., Krolicki, L., Kulinski, R., Koziorowski, D., Janik, P., Rymarczyk, K., Grabowska, A., Kaczmarek, L., Szatkowska, I., 2014. The neural correlates of specific executive dysfunctions in Parkinson's disease. Acta Neurobiol. Exp. (Wars). 74, 465-478. https://doi.org/10.1111/jnp.12028

Geurts, J.J., Barkhof, F., 2008. Grey matter pathology in multiple sclerosis. Lancet Neurol. 7, 841-851. https://doi.org/10.1016/S1474-4422(08)70191-1

Giovannoni, G., Butzkueven, H., Dhib-Jalbut, S., Hobart, J., Kobelt, G., Pepper, G., Sormani, 
M.P., Thalheim, C., Traboulsee, A., Vollmer, T., 2016. Brain health: time matters in multiple sclerosis. Mult. Scler. Relat. Disord. 9, S5-S48.

https://doi.org/10.1016/j.msard.2016.07.003

Goetz, C.G., Tilley, B.C., Shaftman, S.R., Stebbins, G.T., Fahn, S., Martinez-Martin, P., Poewe, W., Sampaio, C., Stern, M.B., Dodel, R., Dubois, B., Holloway, R., Jankovic, J., Kulisevsky, J., Lang, A.E., Lees, A., Leurgans, S., LeWitt, P.A., Nyenhuis, D., Olanow, C.W., Rascol, O., Schrag, A., Teresi, J.A., van Hilten, J.J., LaPelle, N., Agarwal, P., Athar, S., Bordelan, Y., Bronte-Stewart, H.M., Camicioli, R., Chou, K., Cole, W., Dalvi, A., Delgado, H., Diamond, A., Dick, J.P., Duda, J., Elble, R.J., Evans, C., Evidente, V.G., Fernandez, H.H., Fox, S., Friedman, J.H., Fross, R.D., Gallagher, D., Goetz, C.G., Hall, D., Hermanowicz, N., Hinson, V., Horn, S., Hurtig, H., Kang, U.J., KleinerFisman, G., Klepitskaya, O., Kompoliti, K., Lai, E.C., Leehey, M.L., Leroi, I., Lyons, K.E., McClain, T., Metzer, S.W., Miyasaki, J., Morgan, J.C., Nance, M., Nemeth, J., Pahwa, R., Parashos, S.A., Schneider, J.S.J.S., Schrag, A., Sethi, K., Shulman, L.M., Siderowf, A., Silverdale, M., Simuni, T., Stacy, M., Stern, M.B., Stewart, R.M., Sullivan, K., Swope, D.M., Wadia, P.M., Walker, R.W., Walker, R., Weiner, W.J., Wiener, J., Wilkinson, J., Wojcieszek, J.M., Wolfrath, S., Wooten, F., Wu, A., Zesiewicz, T.A., Zweig, R.M., 2008. Movement Disorder Society-Sponsored Revision of the Unified Parkinson's Disease Rating Scale (MDS-UPDRS): Scale presentation and clinimetric testing results. Mov. Disord. 23, 2129-2170.

https://doi.org/10.1002/mds.22340

Gold, B.T., 2015. Lifelong bilingualism and neural reserve against Alzheimer's disease: A review of findings and potential mechanisms. Behav. Brain Res. 281, 9-15. https://doi.org/10.1016/j.bbr.2014.12.006

Gold, B.T., Johnson, N.F., Powell, D.K., 2013a. Lifelong bilingualism contributes to 
cognitive reserve against white matter integrity declines in aging. Neuropsychologia 51, 2841-2846. https://doi.org/10.1016/j.neuropsychologia.2013.09.037

Gold, B.T., Johnson, N.F., Powell, D.K., Smith, C.D., 2012. White matter integrity and vulnerability to Alzheimer's disease: Preliminary findings and future directions. Biochim. Biophys. Acta - Mol. Basis Dis. 1822, 416-422. https://doi.org/10.1016/j.bbadis.2011.07.009

Gold, B.T., Kim, C., Johnson, N.F., Kryscio, R.J., Smith, C.D., 2013b. Lifelong Bilingualism Maintains Neural Efficiency for Cognitive Control in Aging. J. Neurosci. 31, 387-396. https://doi.org/10.1016/j.immuni.2010.12.017.Two-stage

Goldman, J., MD, M.S., Bledsoe, I., MD, M.S., Merkitch, D., Dinh, V., Bernard, B., Stebbins, G., 2017. Corpus callosal atrophy and associations with cognitive impairment in Parkinson disease. Neurology 88, 1265-1272. https://doi.org/10.1212/WNL.0000000000003764

Gollan, T.H., Salmon, D.P., Montoya, R.I., Galasko, D.R., 2011. Degree of bilingualism predicts age of diagnosis of Alzheimer's disease in low-education but not in highly educated Hispanics. Neuropsychologia 49, 3826-3830. https://doi.org/10.1016/j.neuropsychologia.2011.09.041

Grant, A., Dennis, N.A., Li, P., 2014. Cognitive control, cognitive reserve, and memory in the aging bilingual brain. Front. Psychol. https://doi.org/10.3389/fpsyg.2014.01401

Green, D.W., 2009. Mental control of the bilingual lexico-semantic system. Biling. Lang. Cogn. 1, 67. https://doi.org/10.1017/s1366728998000133

Green, D.W., Wei, L., 2016. Code-switching and language control. Bilingualism 19, 883884. https://doi.org/10.1017/S1366728916000018

Grothe, M., Lotze, M., Langner, S., Dressel, A., 2017. Impairments in Walking Ability, Dexterity, and Cognitive Function in Multiple Sclerosis Are Associated with Different 
Regional Cerebellar Gray Matter Loss. Cerebellum 16, 945-950.

https://doi.org/10.1007/s12311-017-0871-8

Grundy, J.G., Anderson, J.A.E., Bialystok, E., 2017. Neural correlates of cognitive processing in monolinguals and bilinguals. Ann. N. Y. Acad. Sci. 183-201. https://doi.org/10.1111/nyas.13333

Gullifer, J.W., Titone, D., 2019. Characterizing the social diversity of bilingualism using language entropy. Bilingualism. https://doi.org/10.1017/S1366728919000026

Guzmán-Vélez, E., Tranel, D., 2015. Does Bilingualism Contribute to Cognitive Reserve? Cognitive and Neural Perspectives. Neuropsychology 29, 139-150. https://doi.org/10.1037/neu0000105.Does

Guzzetti, S., Mancini, F., Caporali, A., Manfredi, L., Daini, R., 2019. The association of cognitive reserve with motor and cognitive functions for different stages of Parkinson's disease. Exp. Gerontol. 115, 79-87. https://doi.org/10.1016/j.exger.2018.11.020

Hall, J.M., Lewis, S.J.G., 2019. Neural Correlates of Cognitive Impairment in Parkinson's Disease: A Review of Structural MRI Findings, 1st ed, International Review of Neurobiology. Elsevier Inc. https://doi.org/10.1016/bs.irn.2018.09.009

Hämäläinen, S., Sairanen, V., Leminen, A., Lehtonen, M., 2017. Bilingualism modulates the white matter structure of language-related pathways. Neuroimage 152, 249-257. https://doi.org/10.1016/j.neuroimage.2017.02.081

Hanganu, A., Bedetti, C., Degroot, C., Mejia-Constain, B., Lafontaine, A.L., Soland, V., Chouinard, S., Bruneau, M.A., Mellah, S., Belleville, S., Monchi, O., 2014. Mild cognitive impairment is linked with faster rate of cortical thinning in patients with Parkinson's disease longitudinally. Brain 137, 1120-1129. https://doi.org/10.1093/brain/awu036

Hattori, T., Orimo, S., Aoki, S., Ito, K., Abe, O., Amano, A., Sato, R., Sakai, K., Mizusawa, 
H., 2012. Cognitive status correlates with white matter alteration in Parkinson's disease. Hum. Brain Mapp. 33, 727-739. https://doi.org/10.1002/hbm.21245

Hedge, C., Powell, G., Sumner, P., 2018. The reliability paradox: Why robust cognitive tasks do not produce reliable individual differences. Behav. Res. Methods 50, 1166-1186. https://doi.org/10.3758/s13428-017-0935-1

Herman, T., Rosenberg-Katz, K., Jacob, Y., Giladi, N., Hausdorff, J.M., 2014. Gray matter atrophy and freezing of gait in Parkinson's disease: Is the evidence black-on-white? Mov. Disord. 29, 134-139. https://doi.org/10.1002/mds.25697

Hervais-Adelman, A., Egorova, N., Golestani, N., 2018. Beyond bilingualism: multilingual experience correlates with caudate volume. Brain Struct. Funct. 223, 3495-3502. https://doi.org/10.1007/s00429-018-1695-0

Hindle, J. V., Martin-Forbes, P.A., Martyr, A., Bastable, A.J.M., Pye, K.L., Mueller Gathercole, V.C., Thomas, E.M., Clare, L., 2017. The effects of lifelong cognitive lifestyle on executive function in older people with Parkinson's disease. Int. J. Geriatr. Psychiatry 32, e157-e165. https://doi.org/10.1002/gps.4677

Hindle, J. V., Martyr, A., Clare, L., 2014. Cognitive reserve in Parkinson's disease: A systematic review and meta-analysis. Park. Relat. Disord. 20, 1-7. https://doi.org/10.1016/j.parkreldis.2013.08.010

Hindle, J. V, Martin-forbes, P.A., Bastable, A.J.M., Pye, K.L., Martyr, A., Whitaker, C.J., Craik, F.I.M., Bialystok, E., Thomas, E.M., Gathercole, V.C.M., Clare, L., Cadwaladr, B., Hospital, L., Ll, C., 2015. Cognitive Reserve in Parkinson's Disease : The Effects of Welsh-English Bilingualism on Executive Function. Park. Dis. 2015, 10. https://doi.org/10.1155/2015/943572

Hobbs, N.Z., Pedrick, A. V., Say, M.J., Frost, C., Dar Santos, R., Coleman, A., Sturrock, A., Craufurd, D., Stout, J.C., Leavitt, B.R., Barnes, J., Tabrizi, S.J., Scahill, R.I., 2011. The 
structural involvement of the cingulate cortex in premanifest and early Huntington's disease. Mov. Disord. 26, 1684-1690. https://doi.org/10.1002/mds.23747

Hofweber, J., Marinis, T., Treffers-Daller, J., 2016. Effects of dense code-switching on executive control. Linguist. Approaches to Biling. 6, 648-668. https://doi.org/10.1075/lab.15052.hof

Jankovic, J., 2008. Parkinson's disease: clinical features and diagnosis. J. Neurol. Neurosurg. Psychiatry 79, 368-376. https://doi.org/10.1136/jnnp.2007.131045

Jubault, T., Gagnon, J.F., Karama, S., Ptito, A., Lafontaine, A.L., Evans, A.C., Monchi, O., 2011. Patterns of cortical thickness and surface area in early Parkinson's disease. Neuroimage 55, 462-467. https://doi.org/10.1016/j.neuroimage.2010.12.043

Julian, L.J., 2011. Cognitive Functioning in Multiple Sclerosis. Neurol. Clin. 29, 507-525. https://doi.org/10.1016/j.ncl.2010.12.003

Kalia, L. V., Lang, A.E., 2015. Parkinson's disease. Lancet 24, 92-98. https://doi.org/10.1016/S0140-6736(14)61393-3

Karran, E., Mercken, M., Strooper, B. De, 2011. The amyloid cascade hypothesis for Alzheimer's disease: An appraisal for the development of therapeutics. Nat. Rev. Drug Discov. 10, 698-712. https://doi.org/10.1038/nrd3505

Kassubek, J., Juengling, F.D., Ecker, D., Landwehrmeyer, G.B., 2005. Thalamic Atrophy in Huntington's Disease Co-varies with Cognitive Performance: A Morphometric MRI Analysis. Cereb. Cortex 15, 846-853. https://doi.org/10.1093/cercor/bhh185

Kassubek, J., Juengling, F.D., Kioschies, T., Henkel, K., Karitzky, J., Kramer, B., Ecker, D., Andrich, J., Saft, C., Kraus, P., Aschoff, A.J., Ludolph, A.C., Landwehrmeyer, G.B., 2004. Topography of cerebral atrophy in early Huntington's disease: a voxel based morphometric MRI study. J. Neurol. Neurosurg. Psychiatry 75, 213-20.

Kavé, G., Eyal, N., Shorek, A., Cohen-Mansfield, J., 2008. Multilingualism and cognitive 
state in the oldest old. Psychol. Aging 23, 70-78. https://doi.org/10.1037/08827974.23.1.70

Kawamura, M., Koyama, S., 2007. Social cognitive impairment in Parkinson's disease. J. Neurol. 254, 49-53. https://doi.org/10.1007/s00415-007-4008-8

Koenig, K.A., Sakaie, K.E., Lowe, M.J., Lin, J., Stone, L., Bermel, R.A., Beall, E.B., Rao, S.M., Trapp, B.D., Phillips, M.D., 2014. Hippocampal volume is related to cognitive decline and fornicial diffusion measures in multiple sclerosis. Magn. Reson. Imaging 32, 354-358. https://doi.org/10.1016/j.mri.2013.12.012

Koerts, J., Tucha, L., Lange, K.W., Tucha, O., 2013. The influence of cognitive reserve on cognition in Parkinson's disease. J. Neural Transm. 120, 593-596. https://doi.org/10.1007/s00702-012-0916-6

Koini, M., Filippi, M., Rocca, M.A., Yousry, T., Ciccarelli, O., Tedeschi, G., Gallo, A., Ropele, S., Valsasina, P., Riccitelli, G., Damjanovic, D., Muhlert, N., Mancini, L., Fazekas, F., Enzinger, C., 2016. Correlates of executive functions in multiple sclerosis based on structural and functional mr imaging: Insights from a multicenter study. Radiology 280, 869-879. https://doi.org/10.1148/radiol.2016151809

Kotagal, V., Bohnen, N.I., Müller, M.L.T.M., Koeppe, R.A., Frey, K.A., Langa, K.M., Albin, R.L., 2015. Educational attainment and motor burden in Parkinson's disease. Mov. Disord. 30, 1143-1147. https://doi.org/10.1002/mds.26272

Kowoll, M.E., Degen, C., Gorenc, L., Küntzelmann, A., Fellhauer, I., Giesel, F., Haberkorn, U., Schröder, J., 2016. Bilingualism as a contributor to cognitive reserve? Evidence from cerebral glucose metabolism in mild cognitive impairment and Alzheimer's disease. Front. Psychiatry 7, 1-6. https://doi.org/10.3389/fpsyt.2016.00062

Kroll, J.F., Stewart, E., 1994. Category Interference in Translation and Picture Naming: Evidence for Asymmetric Connections Between Bilingual Memory Representations. J. 
Mem. Lang. 33, 149-174. https://doi.org/10.1006/jmla.1994.1008

Kudlicka, A., Clare, L., Hindle, J. V., 2011. Executive functions in Parkinson's disease:

Systematic review and meta-analysis. Mov. Disord. 26, 2305-2315.

https://doi.org/10.1002/mds.23868

Lassmann, H., Van Horssen, J., Mahad, D., 2012. Progressive multiple sclerosis: Pathology and pathogenesis. Nat. Rev. Neurol. 8, 647-656.

https://doi.org/10.1038/nrneurol.2012.168

Lee, E.Y., Sen, S., Eslinger, P.J., Wagner, D., Shaffer, M.L., Kong, L., Lewis, M.M., Du, G., Huang, X., 2013. Early cortical gray matter loss and cognitive correlates in nondemented Parkinson's patients. Park. Relat. Disord. 19, 1088-1093. https://doi.org/10.1016/j.parkreldis.2013.07.018

Lehtonen, M., Soveri, A., Laine, A., Järvenpää, J., de Bruin, A., Antfolk, J., 2018. Is bilingualism associated with enhanced executive functioning in adults? A meta-analytic review. Psychol. Bull. 144, 394-425. https://doi.org/10.1037/bul0000142

Leung, I.H.K., Walton, C.C., Hallock, H., Lewis, S.J.G., Valenzuela, M., Lampit, A., 2015. Cognitive training in Parkinson disease: A systematic review and meta-analysis. Neurology 85, 1843-1851. https://doi.org/10.1212/WNL.0000000000002145

Li, X., Xing, Y., Martin-Bastida, A., Piccini, P., Auer, D.P., 2018. Patterns of grey matter loss associated with motor subscores in early Parkinson's disease. NeuroImage Clin. 17, 498-504. https://doi.org/10.1016/j.nicl.2017.11.009

Lindvall, O., Kokaia, Z., 2006. Stem cells for the treatment of neurological disorders. Nature 441, 1094-1096. https://doi.org/10.1038/nature04960

Liu, W., Yang, J., Burgunder, J.M., Cheng, B., Shang, H., 2016. Diffusion imaging studies of Huntington's disease: A meta-analysis. Park. Relat. Disord. 32, 94-101. https://doi.org/10.1016/j.parkreldis.2016.09.005 
Llufriu, S., Martinez-Heras, E., Solana, E., Sola-Valls, N., Sepulveda, M., Blanco, Y.,

Martinez-Lapiscina, E.H., Andorra, M., Villoslada, P., Prats-Galino, A., Saiz, A., 2017.

Structural networks involved in attention and executive functions in multiple sclerosis.

NeuroImage Clin. 13, 288-296. https://doi.org/10.1016/j.nicl.2016.11.026

Lopez-Sendon, J.L., Royuela, A., Trigo, P., Orth, M., Lange, H., Reilmann, R., Keylock, J.,

Rickards, H., Piacentini, S., Squitieri, F., Landwehrmeyer, B., Witjes-Ane, M.-N.,

Jurgens, C.K., Roos, R.A.C., Abraira, V., de Yebenes, J.G., the European HD Network,

2011. What is the Impact of Education on Huntington's Disease? Mov. Disord. 26,

1483-1495. https://doi.org/10.1002/23385

Lotharius, J., Brundin, P., 2002. Pathogenesis of parkinson's disease: Dopamine, vesicles and $\alpha$-synuclein. Nat. Rev. Neurosci. 3, 932-942. https://doi.org/10.1038/nrn983

Lucero, C., Campbell, M.C., Flores, H., Maiti, B., Perlmutter, J.S., Foster, E.R., 2015.

Cognitive reserve and $\beta$-amyloid pathology in Parkinson disease. Park. Relat. Disord.

21, 899-904. https://doi.org/10.1016/j.parkreldis.2015.05.020

Luk, G., Bialystok, E., 2013. Bilingualism is not a categorical variable: Interaction between language proficiency and usage. J. Cogn. Psychol. 25, 605-621.

https://doi.org/10.1080/20445911.2013.795574

Luk, G., Bialystok, E., Craik, F.I.M., Grady, C.L., 2011. Lifelong Bilingualism Maintains

White Matter Integrity in Older Adults. J. Neurosci. 31, 16808-16813.

https://doi.org/10.1523/JNEUROSCI.4563-11.2011

Luk, G., Pliatsikas, C., 2016. Converging diversity to unity: commentary on The neuroanatomy of bilingualism. Lang. Cogn. Neurosci. 31, 349-352.

https://doi.org/10.1080/23273798.2015.1119289

Luo, L., Craik, F.I.M., Moreno, S., Bialystok, E., 2013. Bilingualism interacts with domain in a working memory task: Evidence from aging. Psychol. Aging 28, 28-34. 
https://doi.org/10.1037/a0030875

Majid, D.S.A., Aron, A.R., Thompson, W., Sheldon, S., Hamza, S., Stoffers, D., Holland, D., Goldstein, J., Corey-Bloom, J., Dale, A.M., 2011. Basal ganglia atrophy in prodromal Huntington's disease is detectable over one year using automated segmentation. Mov. Disord. 26, 2544-2551. https://doi.org/10.1002/mds.23912

Mak, E., Su, L., Williams, G.B., Firbank, M.J., Lawson, R.A., Yarnall, A.J., Duncan, G.W., Owen, A.M., Khoo, T.K., Brooks, D.J., Rowe, J.B., Barker, R.A., Burn, D.J., O’Brien, J.T., 2015. Baseline and longitudinal grey matter changes in newly diagnosed Parkinson's disease: ICICLE-PD study. Brain 138, 2974-2986. https://doi.org/10.1093/brain/awv211

Marian, V., Blumenfeld, H.K., Kaushanskaya, M., 2007. The Language Experience and Proficiency Questionnaire (LEAP-Q): Assessing Language Profiles in Bilinguals and Multilinguals. J. Speech, Lang. Hear. Res. 50, 940-967. https://doi.org/10.1044/1092$4388(2007 / 067)$

Martínez-Horta, S., Moreu, A., Perez-Perez, J., Sampedro, F., Horta-Barba, A., Pagonabarraga, J., Gomez-Anson, B., Lozano-Martinez, G.A., Lopez-Mora, D.A., Camacho, V., Fernández-León, A., Carrió, I., Kulisevsky, J., 2018. The impact of bilingualism on brain structure and function in Huntington's disease. Parkinsonism Relat. Disord. 0-1. https://doi.org/10.1016/j.parkreldis.2018.09.017

Miyake, A., Friedman, N.P., Emerson, M.J., Witzki, A.H., Howerter, A., Wager, T.D., 2000. The Unity and Diversity of Executive Functions and Their Contributions to Complex "Frontal Lobe" Tasks: A Latent Variable Analysis. Cogn. Psychol. 41, 49-100. https://doi.org/10.1006/cogp.1999.0734

Mucke, L., 2009. Alzheimer's disease. Nature 461, 895-897. https://doi.org/10.1038/461895a Nithianantharajah, J., Hannan, A.J., 2011. Mechanisms mediating brain and cognitive 
reserve: Experience-dependent neuroprotection and functional compensation in animal models of neurodegenerative diseases. Prog. Neuro-Psychopharmacology Biol. Psychiatry 35, 331-339. https://doi.org/10.1016/j.pnpbp.2010.10.026

Nourbakhsh, B., Nunan-Saah, J., Maghzi, A.H., Julian, L.J., Spain, R., Jin, C., Lazar, A., Pelletier, D., Waubant, E., 2016. Longitudinal associations between MRI and cognitive changes in very early MS. Mult. Scler. Relat. Disord. 5, 47-52. https://doi.org/10.1016/j.msard.2015.10.010

Olsson, T., Barcellos, L.F., Alfredsson, L., 2016. Interactions between genetic, lifestyle and environmental risk factors for multiple sclerosis. Nat. Rev. Neurol. 13, 26-36. https://doi.org/10.1038/nrneurol.2016.187

Ossher, L., Bialystok, E., Craik, F.I.M., Murphy, K.J., Troyer, A.K., 2013. The effect of bilingualism on amnestic mild cognitive impairment. Journals Gerontol. - Ser. B Psychol. Sci. Soc. Sci. 68, 8-12. https://doi.org/10.1093/geronb/gbs038

Ouellette, R., Bergendal, Å., Shams, S., Martola, J., Mainero, C., Kristoffersen Wiberg, M., Fredrikson, S., Granberg, T., 2018. Lesion accumulation is predictive of long-term cognitive decline in multiple sclerosis. Mult. Scler. Relat. Disord. 21, 110-116. https://doi.org/10.1016/j.msard.2018.03.002

Paap, K.R., Greenberg, Z.I., 2013. There is no coherent evidence for a bilingual advantage in executive processing. Cogn. Psychol. 66, 232-258. https://doi.org/10.1016/j.cogpsych.2012.12.002

Paap, K.R., Johnson, H.A., Sawi, O., 2015. Bilingual advantages in executive functioning either do not exist or are restricted to very specific and undetermined circumstances. Cortex 69, 265-278. https://doi.org/10.1016/j.cortex.2015.04.014

Pan, P.L., Shi, H.C., Zhong, J.G., Xiao, P.R., Shen, Y., Wu, L.J., Song, Y.Y., He, G.X., Li, H.L., 2013. Gray matter atrophy in Parkinson's disease with dementia: Evidence from 
meta-analysis of voxel-based morphometry studies. Neurol. Sci. 34, 613-619. https://doi.org/10.1007/s10072-012-1250-3

Papapetropoulos, S., Mash, D.C., 2005. Psychotic symptoms in Parkinson's disease: From description to etiology. J. Neurol. 252, 753-764. https://doi.org/10.1007/s00415-0050918-5

Papathanasiou, A., Messinis, L., Zampakis, P., Panagiotakis, G., Gourzis, P., Georgiou, V., Papathanasopoulos, P., 2015. Thalamic atrophy predicts cognitive impairment in relapsing remitting multiple sclerosis. Effect on instrumental activities of daily living and employment status. J. Neurol. Sci. 358, 236-242. https://doi.org/10.1016/j.jns.2015.09.001

Paplikar, A., Mekala, S., Bak, T.H., Dharamkar, S., Alladi, S., Kaul, S., 2018. Bilingualism and the severity of poststroke aphasia. Aphasiology 00, 1-15.

https://doi.org/10.1080/02687038.2017.1423272

Papoutsi, M., Labuschagne, I., Tabrizi, S.J., Stout, J.C., 2014. The cognitive burden in Huntington's disease: Pathology, phenotype, and mechanisms of compensation. Mov. Disord. 29, 673-683. https://doi.org/10.1002/mds.25864

Paradis, M., 2008. Bilingualism and neuropsychiatric disorders. J. Neurolinguistics 21, 199_ 230. https://doi.org/10.1016/j.jneuroling.2007.09.002

Paulsen, J.S., Magnotta, V.A., Mikos, A.E., Paulson, H.L., Penziner, E., Andreasen, N.C., Nopoulos, P.C., 2006. Brain structure in preclinical Huntington's disease. Biol. Psychiatry 59, 57-63. https://doi.org/10.1016/j.biopsych.2005.06.003

Perani, D., Abutalebi, J., 2015. Bilingualism, dementia, cognitive and neural reserve. Curr. Opin. Neurol. 28, 618-625. https://doi.org/10.1097/WCO.0000000000000267

Perani, D., Farsad, M., Ballarini, T., Lubian, F., Malpetti, M., Fracchetti, A., Magnani, G., March, A., Abutalebi, J., 2017. The impact of bilingualism on brain reserve and 
metabolic connectivity in Alzheimer's dementia. Proc. Natl. Acad. Sci. 114, 1690-1695. https://doi.org/https://doi.org/10.1073/pnas.1610909114

Petersen, R.C., 2016. Mild Cognitive Impairment. Contin. Lifelong Learn. Neurol. 22, 404418. https://doi.org/10.1103/PhysRevE.95.012702

Petersen, R.C., Smith, G.E., Waring, S.C., Ivnik, R.J., Tangalos, E.G., Kokmen, E., 1999. Mild Cognitive Impairment. Arch. Neurol. 56, 303-309.

Petrou, M., Dwamena, B.A., Foerster, B.R., Maceachern, M.P., Bohnen, N.I., Müller, M.L., Albin, R.L., Frey, K.A., 2015. Amyloid deposition in Parkinson's disease and cognitive impairment: A systematic review. Mov. Disord. 30, 928-935. https://doi.org/10.1002/mds.26191

Pini, L., Pievani, M., Bocchetta, M., Altomare, D., Bosco, P., Cavedo, E., Galluzzi, S., Marizzoni, M., Frisoni, G.B., 2016. Brain atrophy in Alzheimer's Disease and aging. Ageing Res. Rev. 30, 25-48. https://doi.org/10.1016/j.arr.2016.01.002

Pliatsikas, C., 2019. Understanding structural plasticity in the bilingual brain: The Dynamic Restructuring Model. Biling. Lang. Cogn. 1-13. https://doi.org/10.1017/S1366728919000130

Pliatsikas, C., DeLuca, V., Voits, T., 2019. The many shades of bilingualism: language experiences modulate adaptations in brain structure. Lang. Learn. (In press)

Pliatsikas, C., Johnstone, T., Marinis, T., 2014. Grey matter volume in the cerebellum is related to the processing of grammatical rules in a second language: A structural voxelbased morphometry study. Cerebellum 13, 55-63. https://doi.org/10.1007/s12311-0130515-6

Pliatsikas, C., Luk, G., 2016. Executive control in bilinguals: A concise review on fMRI studies. Biling. Lang. Cogn. 19, 699-705. https://doi.org/10.1017/S1366728916000249 Pliatsikas, C., Moschopoulou, E., Saddy, D., 2017. Brain Structure and Function Immersive 
late bilingualism reshapes the core of the brain. Brain Struct. Funct. https://doi.org/10.1007/s00429-016-1307-9

Pliatsikas, C., Moschopoulou, E., Saddy, J.D., 2015. The effects of bilingualism on the white matter structure of the brain. Proc. Natl. Acad. Sci. U. S. A. 112, 1334-7. https://doi.org/10.1073/pnas.1414183112

Rao, S.M., Leo, G.J., Haughton, V.M., St. Aubin-Faubert, P., Bernardin, L., 1989. Correlation of magnetic resonance imaging with neuropsychological testing in multiple sclerosis. Neurology 39, 161-166. https://doi.org/10.1212/wnl.39.2.161

Reijnders, J.S.A.M., Ehrt, U., Weber, W.E.J., Aarsland, D., Leentjens, A.F.G., 2008. A systematic review of prevalence studies of depression in Parkinson's disease. Mov. Disord. 23, 183-189. https://doi.org/10.1002/mds.21803

Riccitelli, G., Rocca, M.A., Pagani, E., Martinelli, V., Radaelli, M., Falini, A., Comi, G., Filippi, M., 2012. Mapping regional grey and white matter atrophy in relapsingremitting multiple sclerosis. Mult. Scler. J. 18, 1027-1037. https://doi.org/10.1177/1352458512439239

Roca, M., Torralva, T., Meli, F., Fiol, M., Calcagno, M.L., Carpintiero, S., De Pino, G., Ventrice, F., Martín, M.E., Vita, L., Manes, F., Correale, J., 2008. Cognitive deficits in multiple sclerosis correlate with changes in fronto-subcortical tracts. Mult. Scler. 14, 364-369. https://doi.org/10.1177/1352458507084270

Rocca, M.A., Valsasina, P., Leavitt, V.M., Rodegher, M., Radaelli, M., Riccitelli, G.C., Martinelli, V., Martinelli-Boneschi, F., Falini, A., Comi, G., Filippi, M., 2018. Functional network connectivity abnormalities in multiple sclerosis: Correlations with disability and cognitive impairment. Mult. Scler. J. 24, 459-471. https://doi.org/10.1177/1352458517699875

Roman, C.A.F., Arnett, P.A., 2016. Structural brain indices and executive functioning in 
multiple sclerosis: A review. J. Clin. Exp. Neuropsychol. 38, 261-274. https://doi.org/10.1080/13803395.2015.1105199

Roosendaal, S.D., Geurts, J.J.G., Vrenken, H., Hulst, H.E., Cover, K.S., Castelijns, J.A., Pouwels, P.J.W., Barkhof, F., 2009. Regional DTI differences in multiple sclerosis patients. Neuroimage 44, 1397-1403. https://doi.org/10.1016/j.neuroimage.2008.10.026

Rosas, H.D., Lee, S.Y., Bender, A.C., Zaleta, A.K., Vangel, M., Yu, P., Fischl, B., Pappu, V., Onorato, C., Cha, J.-H., Salat, D.H., Hersch, S.M., Vangel, M., Salat, D.H., Pappu, V., Rosas, H.D., Zaleta, A.K., Yu, P., Onorato, C., Bender, A.C., Lee, S.Y., 2010. Altered white matter microstructure in the corpus callosum in Huntington's disease: Implications for cortical “disconnection.” Neuroimage 49, 2995-3004. https://doi.org/10.1016/j.neuroimage.2009.10.015

Rosas, H.D., Salat, D.H., Lee, S.Y., Zaleta, A.K., Pappu, V., Fischl, B., Greve, D., Hevelone, N., Hersch, S.M., 2008. Cerebral cortex and the clinical expression of Huntington's disease: Complexity and heterogeneity. Brain 131, 1057-1068. https://doi.org/10.1093/brain/awn025

Rosas, H.D., Tuch, D.S., Hevelone, N.D., Zaleta, A.K., Vangel, M., Hersch, S.M., Salat, D.H., 2006. Diffusion tensor imaging in presymptomatic and early Huntington's disease: Selective white matter pathology and its relationship to clinical measures. Mov. Disord. 21, 1317-1325. https://doi.org/10.1002/mds.20979

Ross, C.A., Aylward, E.H., Wild, E.J., Langbehn, D.R., Long, J.D., Warner, J.H., Scahill, R.I., Leavitt, B.R., Stout, J.C., Paulsen, J.S., Reilmann, R., Unschuld, P.G., Wexler, A., Margolis, R.L., Tabrizi, S.J., 2014. Huntington disease: Natural history, biomarkers and prospects for therapeutics. Nat. Rev. Neurol. 10, 204-216. https://doi.org/10.1038/nrneurol.2014.24

Ross, C.A., Tabrizi, S.J., 2011. Huntington's disease: From molecular pathogenesis to 
clinical treatment. Lancet Neurol. 10, 83-98. https://doi.org/10.1016/S14744422(10)70245-3

Scahill, R.I., Hobbs, N.Z., Say, M.J., Bechtel, N., Henley, S.M.D., Hyare, H., Langbehn, D.R., Jones, R., Leavitt, B.R., Roos, R.A.C., Durr, A., Johnson, H., Lehéricy, S., Craufurd, D., Kennard, C., Hicks, S.L., Stout, J.C., Reilmann, R., Tabrizi, S.J., 2013. Clinical impairment in premanifest and early Huntington's disease is associated with regionally specific atrophy. Hum. Brain Mapp. 34, 519-529.

https://doi.org/10.1002/hbm.21449

Scheltens, P., Blennow, K., Breteler, M.M.B., de Strooper, B., Frisoni, G.B., Salloway, S., Van der Flier, W.M., 2016. Alzheimer's disease. Lancet 388, 505-517. https://doi.org/10.1016/j.cub.2018.04.080

Schoonheim, M.M., Hulst, H.E., Brandt, R.B., Strik, M., Wink, A.M., Uitdehaag, B.M.J., Barkhof, F., Geurts, J.J.G., 2015. Thalamus structure and function determine severity of cognitive impairment in multiple sclerosis. Neurology 84, 776-783. https://doi.org/10.1212/WNL.0000000000001285

Schweizer, T.A., Ware, J., Fischer, C.E., Craik, F.I.M.M., Bialystok, E., 2012. Bilingualism as a contributor to cognitive reserve: Evidence from brain atrophy in Alzheimer's disease. Cortex 48, 991-996. https://doi.org/10.1016/j.cortex.2011.04.009

Soltani, M., Fatemeh Emami Dehcheshmeh, S., Moradi, N., Hajiyakhchali, A., Majdinasab, N., Mahmood Latifi, S., Hosseini beidokhti, M., Soltani, C.M., Dehcheshmeh, E.S., 2018. Comparing Executive Functions in Bilinguals and Monolinguals Suffering From Relapsing-Remitting Multiple Sclerosis. J. Mod. Rehabil. 12, 133-139.

Spivey, M.J., Marian, V., 1999. Cross Talk Between Native and Second Languages: Partial Activation of an Irrelevant Lexicon. Psychol. Sci. 10, 281-284.

Stern, Y., 2002. What is cognitive reserve? Theory and research application of the reserve 
concept. J. Int. Neuropsychol. Soc. 8, 448-460.

https://doi.org/10.1017/S1355617702813248

Sulpizio, S., Maschio, N. Del, Mauro, G. Del, Fedeli, D., 2019. Bilingualism as a gradient measure modulates functional connectivity of language and control networks.

Neuroimage 116306. https://doi.org/10.1016/j.neuroimage.2019.116306

Sumowski, J.F., Benedict, R., Enzinger, C., Filippi, M., Geurts, J.J., Hamalainen, P., Hulst, H., Inglese, M., Leavitt, V.M., Rocca, M.A., Rosti-Otajarvi, E.M., Rao, S., 2018.

Cognition in multiple sclerosis: State of the field and priorities for the future. Neurology 90, 278-288. https://doi.org/10.1212/WNL.0000000000004977

Sumowski, J.F., Chiaravalloti, N., Wylie, G., Deluca, J., 2009. Cognitive reserve moderates the negative effect of brain atrophy on cognitive efficiency in multiple sclerosis. J. Int. Neuropsychol. Soc. 15, 606-612. https://doi.org/10.1017/S1355617709090912

Sumowski, J.F., Rocca, M.A., Leavitt, V.M., Riccitelli, G., Meani, A., Comi, G., Filippi, M., 2016. Reading, writing, and reserve: Literacy activities are linked to hippocampal volume and memory in multiple sclerosis. Mult. Scler. 22, 1621-1625. https://doi.org/10.1177/1352458516630822

Swerdlow, R.S., 2007. Pathogenesis of Alzheimer disease. Clin. Interv. Aging 2, 347-359. https://doi.org/10.2298/VSP0711765P

Ternes, A.M., Clough, M., Foletta, P., White, O., Fielding, J., 2019. Executive control deficits correlate with reduced frontal white matter volume in multiple sclerosis. J. Clin. Exp. Neuropsychol. 41, 723-729. https://doi.org/10.1080/13803395.2019.1614536

Thompson, A.J., Baranzini, S.E., Geurts, J., Hemmer, B., Ciccarelli, O., 2018. Multiple sclerosis. Lancet 391, 1622-1636. https://doi.org/10.1016/S0140-6736(18)30481-1

Tillema, J.M., Hulst, H.E., Rocca, M.A., Vrenken, H., Steenwijk, M.D., Damjanovic, D., Enzinger, C., Ropele, S., Tedeschi, G., Gallo, A., Ciccarelli, O., Rovira, A., Montalban, 
X., De Stefano, N., Stromillo, M.L., Filippi, M., Barkhof, F., 2016. Regional cortical thinning in multiple sclerosis and its relation with cognitive impairment: A multicenter study. Mult. Scler. 22, 901-909. https://doi.org/10.1177/1352458515607650

Trembath, M.K., Horton, Z.A., Tippett, L., Hogg, V., Collins, V.R., Churchyard, A., Velakoulis, D., Roxburgh, R., Delatycki, M.B., 2010. A retrospective study of the impact of lifestyle on age at onset of huntington disease. Mov. Disord. 25, 1444-1450. https://doi.org/10.1002/mds.23108

Valian, V., 2015. Bilingualism and cognition. Biling. Lang. Cogn. 18, 3-24. https://doi.org/10.1017/S1366728914000522

Vasconcellos, L.F., Pereira, J.S., Adachi, M., Greca, D., Cruz, M., Malak, A.L., CharchatFichman, H., 2018. Volumetric brain analysis as a predictor of a worse cognitive outcome in Parkinson's disease. J. Psychiatr. Res. 102, 254-260. https://doi.org/10.1016/j.jpsychires.2018.04.016

Walker, F.O., 2007. Huntington's disease. Lancet 369, 218-228. https://doi.org/10.1016/S0140-6736(07)60111-1

Watson, G.S., Leverenz, J.B., 2010. Profile of cognitive impairment in parkinson's disease. Brain Pathol. 20, 640-645. https://doi.org/10.1111/j.1750-3639.2010.00373.x

Weier, K., Penner, I.K., Magon, S., Amann, M., Naegelin, Y., Andelova, M., Derfuss, T., Stippich, C., Radue, E.W., Kappos, L., Sprenger, T., 2014. Cerebellar abnormalities contribute to disability including cognitive impairment in multiple sclerosis. PLoS One 9. https://doi.org/10.1371/journal.pone.0086916

Wen, M.C., Ng, A., Chander, R.J., Au, W.L., Tan, L.C.S., Kandiah, N., 2015. Longitudinal brain volumetric changes and their predictive effects on cognition among cognitively asymptomatic patients with Parkinson's disease. Park. Relat. Disord. 21, 483-488. https://doi.org/10.1016/j.parkreldis.2015.02.014 
Wilson, H., Niccolini, F., Pellicano, C., Politis, M., 2019. Cortical thinning across Parkinson's disease stages and clinical correlates. J. Neurol. Sci. 398, 31-38. https://doi.org/10.1016/j.jns.2019.01.020

Wolf, R.C., Sambataro, F., Vasic, N., Schönfeldt-Lecuona, C., Ecker, D., Landwehrmeyer, B., 2008. Aberrant connectivity of lateral prefrontal networks in presymptomatic Huntington's disease. Exp. Neurol. 213, 137-144. https://doi.org/10.1016/j.expneurol.2008.05.017

Woumans, E., Santens, P., Sieben, A., Versijpt, J., Stevens, M., Duyck, W., 2015. Bilingualism delays clinical manifestation of Alzheimer's disease. Biling. Lang. Cogn. 18, 568-574. https://doi.org/doi:10.1017/S136672891400087X.

Wray, S., Fox, N.C., 2016. Stem cell therapy for Alzheimer's disease: Hope or hype? Lancet Neurol. 15, 133-135. https://doi.org/10.1016/S1474-4422(15)00382-8

Yildiz, M., Tettenborn, B., Radue, E.W., Bendfeldt, K., Borgwardt, S., 2014. Association of cognitive impairment and lesion volumes in multiple sclerosis - A MRI study. Clin. Neurol. Neurosurg. 127, 54-58. https://doi.org/10.1016/j.clineuro.2014.09.019

Yousaf, T., Wilson, H., Politis, M., 2017. Imaging the Nonmotor Symptoms in Parkinson's Disease, 1st ed, International Review of Neurobiology. Elsevier Inc. https://doi.org/10.1016/bs.irn.2017.05.001

Zahodne, L.B., Schofield, P.W., Farrell, M.T., Stern, Y., Manly, J.J., 2014. Bilingualism does not alter cognitive decline or dementia risk among spanish-speaking immigrants. Neuropsychology 28, 238-246. https://doi.org/10.1037/neu0000014

Zarei, M., Damoiseaux, J.S., Morgese, C., Beckmann, C.F., Smith, S.M., Matthews, P.M., Scheltens, P., Rombouts, S.A.R.B., Barkhof, F., 2009. Regional White Matter Integrity Differentiates Between Vascular Dementia and Alzheimer Disease. Stroke 40, 773-779. https://doi.org/10.1161/STROKEAHA.108.530832 
Zou, L., Ding, G., Abutalebi, J., Shu, H., Peng, D., 2012. Structural plasticity of the left caudate in bimodal bilinguals. Cortex 48, 1197-1206.

https://doi.org/10.1016/j.cortex.2011.05.022 